\title{
Blood, sweat, and tears: extraterrestrial regolith biocomposites with in vivo binders
}

\author{
A.D. Roberts ${ }^{\mathrm{a}, \mathrm{d}}$, D.R. Whittall ${ }^{\mathrm{a}}$, R. Breitling ${ }^{\mathrm{a}}$, E. Takano ${ }^{\mathrm{a}, \mathrm{d}}$, J.J. Blaker ${ }^{\mathrm{b}, \mathrm{c}}$, S. Hay ${ }^{\mathrm{a}}$, \\ N.S. Scrutton ${ }^{\mathrm{a}, *, \mathrm{~d}}$ \\ ${ }^{a}$ Manchester Institute of Biotechnology and Department of Chemistry, The University of Manchester, M1 7DN, UK \\ ${ }^{\mathrm{b}}$ Department of Materials and Henry Royce Institute, The University of Manchester, Manchester M13 9PL, United Kingdom \\ ${ }^{\mathrm{c}}$ Department of Biomaterials, Institute of Clinical Dentistry, University of Oslo, Oslo 0317, Norway
}

\section{A R T I C L E I N F O}

\section{Keywords:}

Human serum albumin

Hybrid materials

In situ resource utilization

Biopolymer-bound soil composites

Recombinant spider silk

3D-printing

\begin{abstract}
A B S T R A C T
The proverbial phrase 'you can't get blood from a stone' is used to describe a task that is practically impossible regardless of how much force or effort is exerted. This phrase is well-suited to humanity's first crewed mission to Mars, which will likely be the most difficult and technologically challenging human endeavor ever undertaken. The high cost and significant time delay associated with delivering payloads to the Martian surface means that exploitation of resources in situ - including inorganic rock and dust (regolith), water deposits, and atmospheric gases - will be an important part of any crewed mission to the Red Planet. Yet there is one significant, but chronically overlooked, source of natural resources that will — by definition — also be available on any crewed mission to Mars: the crew themselves. In this work, we explore the use of human serum albumin (HSA) - a common protein obtained from blood plasma - as a binder for simulated Lunar and Martian regolith to produce so-called 'extraterrestrial regolith biocomposites (ERBs).' In essence, HSA produced by astronauts in vivo could be extracted on a semi-continuous basis and combined with Lunar or Martian regolith to 'get stone from blood', to rephrase the proverb. Employing a simple fabrication strategy, HSA-based ERBs were produced and displayed compressive strengths as high as $25.0 \mathrm{MPa}$. For comparison, standard concrete typically has a compressive strength ranging between 20 and $32 \mathrm{MPa}$. The incorporation of urea - which could be extracted from the urine, sweat, or tears of astronauts - could further increase the compressive strength by over 300\% in some instances, with the best-performing formulation having an average compressive strength of $39.7 \mathrm{MPa}$. Furthermore, we demonstrate that HSA-ERBs have the potential to be 3D-printed, opening up an interesting potential avenue for extraterrestrial construction using human-derived feedstocks. The mechanism of adhesion was investigated and attributed to the dehydration-induced reorganization of the protein secondary structure into a densely hydrogenbonded, supramolecular $\beta$-sheet network — analogous to the cohesion mechanism of spider silk. For comparison, synthetic spider silk and bovine serum albumin (BSA) were also investigated as regolith binders — which could also feasibly be produced on a Martian colony with future advancements in biomanufacturing technology.
\end{abstract}

\section{Introduction}

Without an appreciable atmosphere or magnetosphere for protection, exposure to galactic cosmic radiation, solar particle events and micrometeor strikes poses a significant survival risk to any crewed mission to Mars or long-term mission to the Lunar surface [1,2]. Due to the high cost of extra-orbital payload delivery, early extraterrestrial colonies will likely exploit loose unconsolidated rock and dust (also known as regolith) as a bulk material for radiation and meteor shielding [2]. The loose, particulate nature of Lunar and Martian regolith will likely necessitate some form of mechanical stabilization to prevent erosion from high-velocity exhaust plumes or Martian dust storms - wind speeds on Mars can exceed $100 \mathrm{~km}$ per hour [3]. Strongly bonded extraterrestrial regolith, combined with a pressurized internal liner, could also serve as a

Abbreviations: ERB, Extraterrestrial Regolith Biocomposite; HSA, Human Serum Albumin; BSA, Bovine Serum Albumin; MSA, Mammalian Serum Albumin; LHS-1, Lunar Highlands Simulant 1; MGS-1, Martian Global Simulant 1; CD, Circular Dichroism; FE-SEM, Field-emission Scanning Electron Microscopy.

* Corresponding author.

E-mail address: Nigel.Scrutton@manchester.ac.uk (N.S. Scrutton).

${ }^{\mathrm{d}}$ EPSRC/BBSRC Future Biomanufacturing Research Hub. 
cost-effective construction material for habitat expansion [4]. Several NASA-backed companies are currently developing additive manufacturing (3D-printing) technologies for extraterrestrial habitat construction based on in situ regolith with suitable binders [5].

Although regolith binders could be produced on Earth (ex situ) and delivered to the colonies, if binders could be produced in situ using resources available onsite (so-called in situ resource utilization, ISRU), this could provide a significant reduction in payload mass and mission cost [2]. The feasibility of producing in situ binders based on biological, synthetic polymer, inorganic, or cement-based materials has been explored and evaluated by others [6-8]. Numerous significant hurdles still remain before such approaches can realistically be employed - largely due to heavy equipment and spare parts needing to be transported from Earth, which would increase mission complexity and largely offset the benefit of employing ISRU [6]. For a crewed mission to Mars, any such equipment would also have to guarantee ultra-high reliability and redundancy since the delivery of any replacement equipment or components from Earth will be restricted by limited launch windows and long travel times [1]. The exploitation of natural resources produced by the astronauts themselves (in vivo) has received surprisingly little attention, despite the ready availability — by definition - of such resources on any crewed mission.

Adhesives and binders of biological origin were widely utilized by humanity for millennia before the development of synthetic petroleumderived adhesives. Tree resins, collagen from hooves, casein from cheese, and animal blood were all used as binders and additives for various applications [9-11]. With relatively recent advances in our understanding of protein structure and function, the ability to create designer proteins through synthetic biology, and the need to move away from petrochemical-based feedstocks, there is a renewed interest in employing biopolymers for material applications and construction [12-17].

In this work, we explore the use of human serum albumin (HSA) as a binder for the fabrication of ERBs. We found that ERBs comprised of nothing but simulated moon or Mars regolith, HSA, and water could have ultimate compressive strengths (UCSs) as high as 25.0 MPa - which compares exceptionally well against other proposed regolith stabilization technologies (Table 1). HSA is the most abundant protein in human blood plasma, present at a concentration of $40-45 \mathrm{~g} \mathrm{~L}^{-1}$, and is replenished at a rate of $12-25 \mathrm{~g} \mathrm{day}^{-1}$ in healthy adults [18]. HSA could be obtained from crew members through blood plasma extraction - an established procedure on Earth, which can safely be performed multiple times a week via a procedure similar to blood donation [19]. If HSA-ERBs were utilized as a mortar and combined with a sandbag-based construction method, our calculations suggest that each crew member - over the course of a 72-week Mars mission - could produce enough HSA to construct habitat-space to support an additional astronaut (details of calculation in SI). This could allow the steady expansion of a nascent Martian colony. Unlike other proposed binder materials, HSA production does not require any additional synthesis technology such as bioreactors or synthetic polymer/resin production equipment - which would add additional mass (and therefore expense) to a Martian mission, as well as increase energy-, water-, and workload-demand, and also be susceptible to component failure. Aside from acting as a mortar-like binder for sandbag-based construction, we also demonstrate the potential for HSA-ERBs to be 3D-printed, which could be a more feasible construction method on Mars and was a target of a recent centennial competition hosted by NASA [5]. We also demonstrate that HSA can strongly adhere to glass, meaning that melted or sintered glassy regolith bricks could potentially be bonded together by HSA-based adhesives or HSA-ERB mortars.

Other in situ human resources, such as hair and nails (keratin), dead skin cells (collagen), mucus, urine, and human feces, could also be exploited for their material properties on early extraterrestrial colonies. In this study, we explored the incorporation of urea - the most abundant constituent of human urine after water - into HSA-ERBs. As a protein denaturant, urea was hypothesized to affect the cohesive strength of HSA-ERBs since the proposed bonding mechanism is dependent on protein unfolding into a more thermodynamically stable $\beta$-sheet-rich

\section{Table 1}

Comparison of the mechanical properties and processing energy requirement of several other regolith stabilization technologies, including primary disadvantages of each technique. Note that quantitative data for processing energy requirements were not available for all sources, so qualitative data (low/medium/ high) were presented in these instances.

\begin{tabular}{|c|c|c|c|c|}
\hline Method & $\begin{array}{l}\text { UCS } \\
\text { (MPa) }\end{array}$ & $\begin{array}{l}\text { Processing } \\
\text { energy } \\
(\mathrm{kWh} / \mathrm{MT})\end{array}$ & Primary disadvantages & Refs. \\
\hline $\begin{array}{l}\text { Melted and cast } \\
\text { regolith }\end{array}$ & 550 & $\begin{array}{l}360 \text { (very } \\
\text { high) }\end{array}$ & $\begin{array}{l}\text { Extremely high } \\
\text { processing energy and } \\
\text { temperature } \\
\left(1200-1500^{\circ} \mathrm{C}\right)\end{array}$ & {$[7,20]$} \\
\hline Sintered regolith & 14.5 & 156 (high) & $\begin{array}{l}\text { High processing energy } \\
\text { and temperature } \\
\left(1000-1200^{\circ} \mathrm{C}\right)\end{array}$ & $\begin{array}{l}{[7,20,} \\
21]\end{array}$ \\
\hline $\begin{array}{l}\text { Extraterrestrial } \\
\text { concrete }\end{array}$ & 75.5 & High & $\begin{array}{l}\text { High processing energy } \\
\text { and water consumption. } \\
\text { Geographically sparse } \\
\text { precursors }\end{array}$ & [7] \\
\hline $\begin{array}{l}\text { Sulfur-bound } \\
\text { regolith }\end{array}$ & 30 & High & $\begin{array}{l}\text { High processing energy. } \\
\text { Susceptible to } \\
\text { sublimation }\end{array}$ & {$[7,20]$} \\
\hline Sand-bagging & 2 & Low & $\begin{array}{l}\text { Poor mechanical } \\
\text { properties. Ex situ bags } \\
\text { needed }\end{array}$ & [20] \\
\hline ERBs with BSA & 19.5 & Low & $\begin{array}{l}\text { Bringing cows to Mars is } \\
\text { not feasible with current } \\
\text { technology }\end{array}$ & $\begin{array}{l}\text { This } \\
\text { study } \\
{[20] \text {, }}\end{array}$ \\
\hline ERBs with HSA & 25.0 & Low & $\begin{array}{l}\text { Limited production. } \\
\text { Potentially detrimental } \\
\text { to crew wellbeing }\end{array}$ & $\begin{array}{l}\text { This } \\
\text { study }\end{array}$ \\
\hline $\begin{array}{l}\text { ERBs with HSA } \\
\text { and urea }\end{array}$ & 39.7 & Low & $\begin{array}{l}\text { Limited production. } \\
\text { Potentially detrimental } \\
\text { to crew wellbeing }\end{array}$ & $\begin{array}{l}\text { This } \\
\text { study }\end{array}$ \\
\hline $\begin{array}{l}\text { ERBs with } \\
\text { synthetic } \\
\text { spider silk }\end{array}$ & $\mathrm{n} / \mathrm{a}$ & $\begin{array}{l}\text { Low/ } \\
\text { Medium }\end{array}$ & $\begin{array}{l}\text { Low technology } \\
\text { readiness }\end{array}$ & $\begin{array}{l}\text { This } \\
\text { study }\end{array}$ \\
\hline $\begin{array}{l}\text { ERBs with } \\
\text { natural spider } \\
\text { silk }\end{array}$ & $\mathrm{n} / \mathrm{a}$ & Low & $\begin{array}{l}\text { Spiders are difficult to } \\
\text { farm for silk }\end{array}$ & - \\
\hline
\end{tabular}

confirmation. The incorporation of urea was found to increase the compressive strength of the HSA-ERBs by up to $300 \%$ (UCS of $39.7 \mathrm{MPa}$ ), while also increasing the density and light-atom content - which would likely improve the radiation-shielding potential of the materials [7]. The demonstration that frozen human feces does not produce effective knives recently won the 2020 Ig Nobel prize for Materials Science [22,23]; however, the low Martian surface temperatures (as low as $-63^{\circ} \mathrm{C}$ ) and pressures could potentially make frozen or desiccated feces-based tools feasible - especially if combined as a composite material with Martian regolith and other human-derived feedstocks such HSA or urea. Unfortunately, due to health and safety concerns, we were unable to explore human feces-based ERBs in this study.

If HSA turns out to be unviable as a binder due to the physiological burden on the astronauts, mammalian serum albumin (MSA) from the plasma of cows, rabbits, goats, or other non-human species could also potentially be employed. We demonstrate that bovine serum albumin (BSA) has similar properties to HSA as a regolith binder, suggesting that the serum albumin from other mammals would also suffice. BSA-based ERBs have been explored extensively by D. Loftus and co-workers [20, 24-27]; our work suggests that HSA-based biocomposites would have analogous properties. The presence of non-human mammals on a Lunar or Martian mission would bring its own significant challenges, summarized in Table S1, but may also provide benefits such as a psychological boost to the astronauts, as well as a supplemental source of food (eggs, milk, meat, etc.) and materials (wool, leather, bone, etc.).

Synthetic (recombinant) proteins produced through microbial expression could be a more feasible option than bringing live animals into space. In this study, we also briefly investigated the feasibility of producing ERBs using a binder based on recombinant spider-silk which could feasibly be produced on the surface of Mars if a self- 
contained ultrahigh reliability and minimal-waste bioreactor could be designed to operate on the planet [28]. Native spider silk could also potentially be produced, with spiders having already been extensively studied onboard the International Space Station (ISS) [29]. Fig. 1 depicts how HSA production could be incorporated with other critical systems needed for a closed-loop Martian habitat and eventually supplemented or superseded by a flexible bioreactor-based system [28,30,31]. The use of spider silk further supports the proposed mechanism of material cohesion being due to hydrogen bonding since the cohesive and adhesive strength of natural spider silk is attributed to the formation of densely hydrogen-bonded $\beta$-sheet networks [32].

\section{Materials and methods}

\subsection{ERB fabrication procedure}

In a typical procedure, $3 \mathrm{~g}$ of HSA (purchased from Sigma-Aldrich, lyophilized powder, $>96 \%$ purity by agarose gel electrophoresis) was dissolved in $7 \mathrm{~g}$ of deionized (DI) water with gentle mixing at $40{ }^{\circ} \mathrm{C}$ to produce a $30 \mathrm{wt} \%$ solution. The density of water was taken as $1 \mathrm{~g} \mathrm{~mL}^{-1}$ and measured volumetrically. Note, higher mixing temperatures $\left(>60{ }^{\circ} \mathrm{C}\right.$ ) will cause the protein to denature and form a gel. The solution would be used within $48 \mathrm{~h}$ and kept at $4{ }^{\circ} \mathrm{C}$ when not in use.

Meanwhile, approximately $4 \mathrm{~g}$ of either Lunar Highlands Simulant 1 (LHS-1) or Martian Global Simulant 1 (MGS-1) (purchased from Exolith Lab, USA) were loaded into a $5 \mathrm{~mL}$ syringe (Omnifix ${ }^{\circledR}$ Luer-Lock, VWR International) and lightly packed with the syringe plunger manually. The precise composition of LHS-1 and MGS-1 is given in the SI. Following this, the HSA solution was infused into the pores of the regolith powder via another syringe, connected with Luer-lock attachments and PTFE tubing (Fig. 2). Note that small incisions were made at the end of the regolith-containing syringe with a razor blade to allow for pressure equalization. The masses of each empty syringe, syringe with regolith, and syringe with regolith and HSA solution were measured to allow for the calculation of binder-to-regolith mass ratio. The HSA-solution infused regolith syringes were then placed on a hot plate maintained at $65{ }^{\circ} \mathrm{C}$

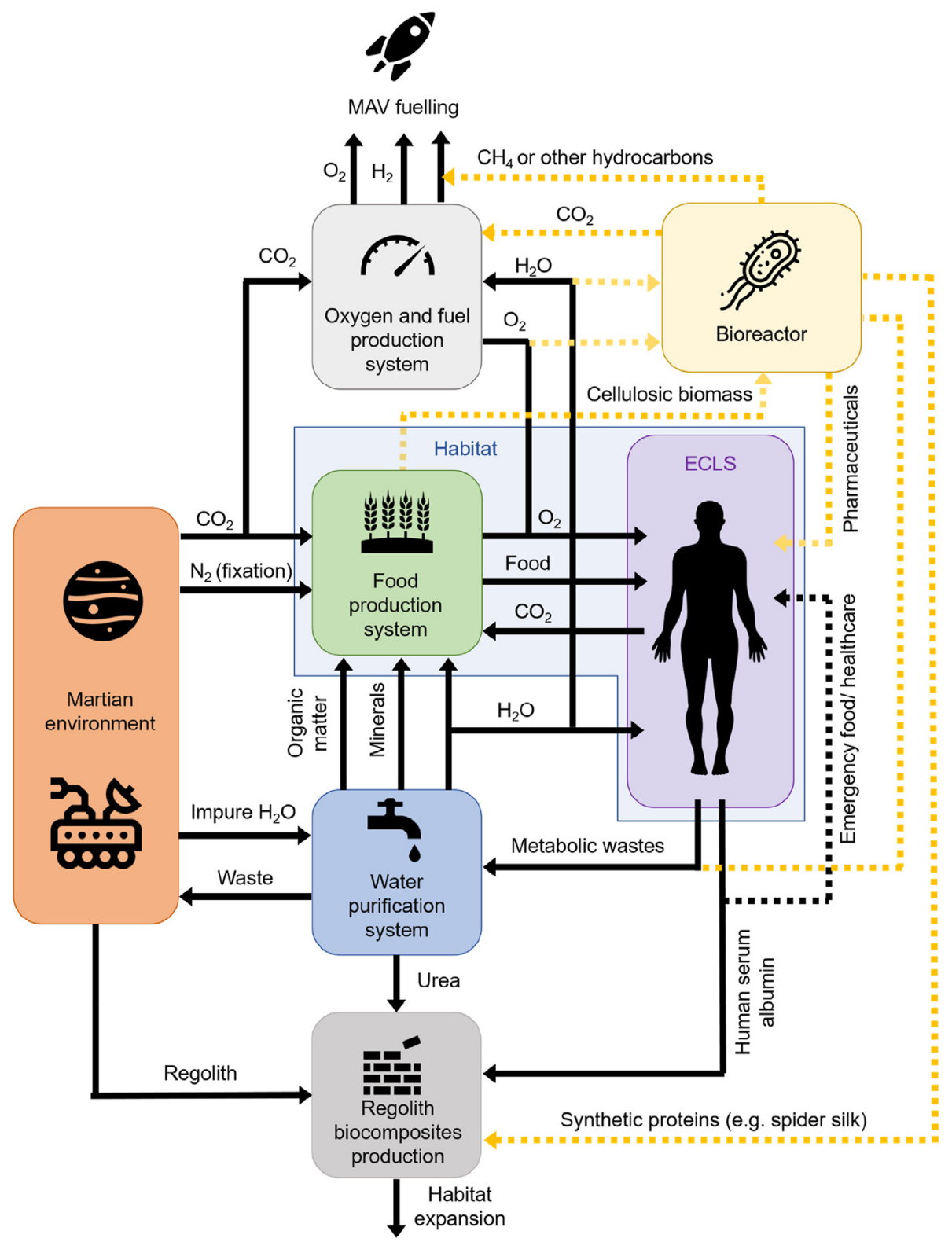

Fig. 1. A hypothetical block diagram depicting how HSA could be produced in vivo from in situ resources available on Mars, and — technological advancements permitting - eventually supplemented or replaced with an ultra-high reliability self-contained bioreactor (dashed yellow arrows) that could have additional uses [28, 30]. Abbreviations: Environmental Control and Life Support (ECLS), Mars Ascent Vehicle (MAV). 
overnight ( $c a .20 \mathrm{~h}$ ) with occasional removal of the supporting plastic syringe within the first $5 \mathrm{~h}$ to facilitate dehydration and hardening.

For the ERBs containing urea, the same procedure was employed, except solutions of urea (up to $3 \mathrm{M}$ concentration) in DI water were employed as the solvent rather than DI water alone. The density of the urea solutions was taken as $1 \mathrm{~g} \mathrm{~mL}^{-1}$.

\subsection{Uniaxial compression tests}

To determine the UCS and stiffness of the ERBs we followed ASTM International Active Standard C39/C39M - 20 (Standard Test Method for Compressive Strength of Cylindrical Concrete Specimens). Briefly, the cylindrical ERB samples of $12.1 \mathrm{~mm}$ in diameter and roughly twice the length ( $\sim 24-30 \mathrm{~mm})$ were subject to uniaxial compression tests using an Instron 5569 Series Universal Testing System (Instron Ltd., USA) that had been compliance corrected using a tungsten carbide disk. Before testing, the ERBs were sanded down manually with Emery paper until an even surface was achieved. The tests were conducted using a $5 \mathrm{kN}$ load cell at a rate of $1 \mathrm{~mm} \mathrm{~min}^{-1}$ and continued until either sudden failure of the sample ( $40 \%$ drop in UCS) or if the sample was determined to have failed through visual inspection. The failure type was generally either type 2 or type 3 according to ASTM C39/C39M - 20 classification, with large vertical cracks propagating through the sample in line with the axis of compression (Fig. S1). The tests were conducted at ambient temperature and humidity, with sample ages ranging from a few weeks to about three months.

\subsection{Circular dichroism}

Circular Dichroism (CD) measurements were taken using a Chirascan V100 (Applied Photophysics, UK) through a method analogous to our previous publication on BSA and recombinant spider silk [17]. Briefly, $5 \mu \mathrm{L}$ of HSA in DI water at $5 \mathrm{wt} \%$ concentration was drop-cast between two quartz substrates before a scan was taken between $190 \mathrm{~nm}$ and $300 \mathrm{~nm}$, followed by subsequent scans every $60 \mathrm{~min}$ for $20 \mathrm{~h}$. Note that higher HSA concentrations could not be employed as this would saturate the UV detector. The sample chamber was maintained at $25^{\circ} \mathrm{C}$, and the path length was approximated as $2 \times 10^{-4} \mathrm{~cm}$ and assumed not to change over the duration of the measurement. The sample acquisition time was 12 min per spectrum (3s per point). For the thermal denaturation study, HSA in water at $0.4 \mathrm{wt} \%$ concentration was aliquoted into a quartz cuvette with a $0.1 \mathrm{~mm}$ path length. Higher HSA concentrations again could not be employed due to saturation of the UV detector. A CD scan was taken (between $190 \mathrm{~nm}$ and $300 \mathrm{~nm}$ ) initially at $25^{\circ} \mathrm{C}$ and then at every $10^{\circ} \mathrm{C}$ intervals up to $85^{\circ} \mathrm{C}$, before declining at each $10^{\circ} \mathrm{C}$ intervals back to $25^{\circ} \mathrm{C}$. Sample acquisition time was 5 min per spectrum (1 s per point) with a 2 min settling time between measurements to allow for thermal equilibration.

Protein secondary structure was determined using the online CD spectra analysis tool BeStSel, which fits experimental CD curves by the linear combination of the fixed basis components to calculate the relative proportion of the eight structural elements. Further details on the algorithms employed are available at http://bestsel.elte.hu/index.php or in Ref. [33].

\subsection{Field-emission scanning electron microscopy (FE-SEM)}

SEM images were taken on a Quanta 250 FE-SEM using secondary electron detection with an accelerating voltage of $8 \mathrm{kV}$ and a working distance of $10 \mathrm{~mm}$. Samples were adhered to aluminum studs with conductive carbon tape and sputter coated with $\mathrm{Au}(\sim 10 \mathrm{~nm}$ thickness) prior to imaging to enhance electrical conductivity.

\subsection{Adhesive tests}

Adhesion tests were conducted in an analogous manner to our previous publication, following ASTM International Active Standard D2919 [17]. Briefly, $5 \mu \mathrm{L}$ of $30 \mathrm{wt} \% \mathrm{HSA}$ in water was drop-cast onto a $2.6 \mathrm{~cm}$ width glass microscope slide (Fischer Scientific, Cat. No. 7101) before being laminated with another slide with an overlap of $0.5 \mathrm{~cm}$ - giving a total shear area of $1.3 \mathrm{~cm}^{2}$. Note that each glass slide was doubled up by adhesion with cyanoacrylate adhesive (Loctite ${ }^{\circledR}$ Superglue) to mitigate against substrate failure prior to adhesive failure [17]. The substrate-adhesive laminate was then compressed under mild pressure by the application of small $(1.5 \mathrm{~cm}$ length) bulldog clips and left to bond under ambient conditions for a minimum of $30 \mathrm{~h}$. The samples were subjected to single-lap shear adhesion tests under compression using an Instron 3340 Series Uniaxial Tensile Tester (Instron Ltd., USA) equipped with a $2 \mathrm{kN}$ Load cell. The compression rate was $0.5 \mathrm{~mm} \mathrm{~min}^{-1}$, and the tests were conducted under ambient temperature and humidity. A cyanoacrylate adhesive (Loctite ${ }^{\circledR}$ superglue) was also tested under analogous conditions to have a side-by-side comparison of performance under the same test conditions.

\subsection{Recombinant spider silk expression and purification}

The recombinant spider silk protein $\left(\mathrm{N}-\mathrm{R}_{7}-\mathrm{C}\right)$ used in this study was cloned and expressed as described by Finnigan et al. [34] Protein expression was performed using E. coli BL21 (DE3) cells cultured in Terrific Broth media supplemented with $100 \mu \mathrm{g} \mathrm{l}^{-1}$ kanamycin. Transformed cultures were incubated at $37^{\circ} \mathrm{C}$ and $180 \mathrm{rpm}$. Upon reaching an optical density at $600 \mathrm{~nm}$ of 0.8 , cell cultures were induced by the addition of IPTG to a final concentration of $0.2 \mathrm{mM}$. Following induction, the incubation temperature was lowered to $20{ }^{\circ} \mathrm{C}$ for overnight

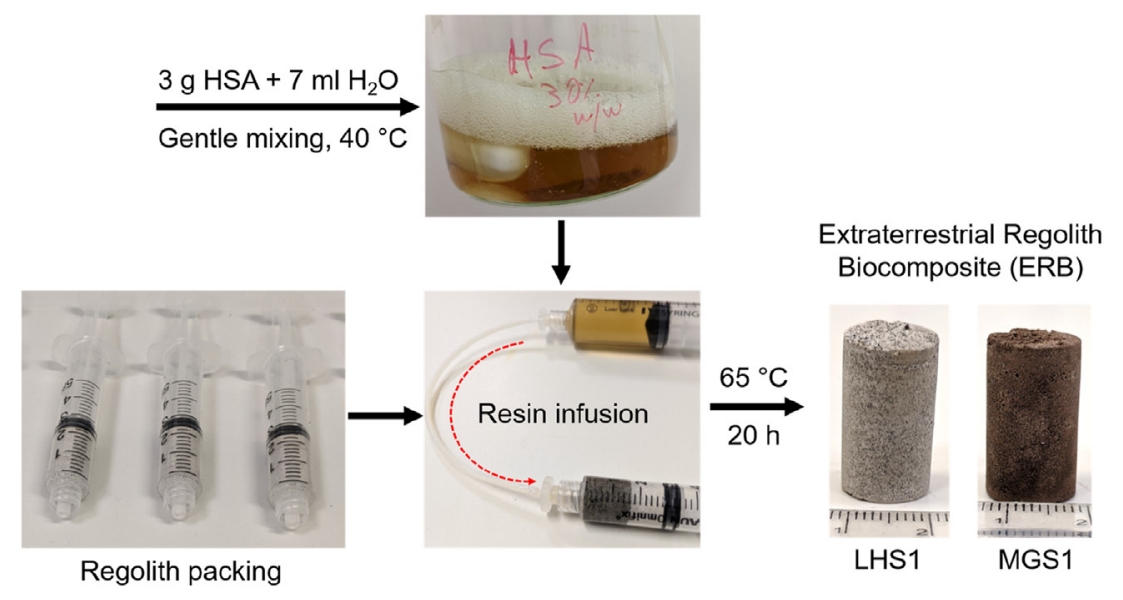

Fig. 2. Scheme depicting the typical fabrication procedure for producing HSA-based ERBs. 
expression. Cells were pelleted by centrifugation, resuspended in ice-cold buffer ( $25 \mathrm{mM}$ Tris- $\mathrm{HCl}, 300 \mathrm{mM} \mathrm{NaCl}, 10 \mathrm{mM}$ imidazole), and lysed by sonication on ice. Soluble protein was separated from insoluble cell debris by centrifugation. Recombinant silk protein was purified from the resulting supernatant by immobilized metal affinity chromatography using Ni-NTA resin and eluted using resuspension buffer containing $250 \mathrm{mM}$ imidazole. Eluted protein was extensively dialyzed against $25 \mathrm{mM}$ Tris- $\mathrm{HCl}, \mathrm{pH} 8.0$ at $4{ }^{\circ} \mathrm{C}$ to remove salt and imidazole. Aggregated silk proteins were removed via centrifugation. Purified silk protein was concentrated using VivaSpin ultrafiltration columns with a molecular weight cut-off of $10 \mathrm{kDa}$. Protein expression and purification were analyzed using SDS-PAGE (Fig. S2). The concentration of purified silk protein was determined in triplicate using a Nanodrop 2000 spectrophotometer. The $\mathrm{A}_{280}$ extinction coefficient and molecular weight of recombinant spider silk protein N-R $-\mathrm{C}\left(21890 \mathrm{M}^{-1} \mathrm{~cm}^{-1}\right.$ and 34862.91 Da, respectively) were calculated using the ExPaSy ProtParam tool [35].

\section{Results}

\subsection{Conceptualization and initial scoping experiments}

Following the earlier work where we investigated the adhesion properties of BSA and recombinant spider silk on glass and other transparent substrates [17], it was hypothesized that BSA could also act as a binder for silicate-rich particulate materials such as sand or extraterrestrial regolith. A literature search revealed that extensive background work had already been undertaken by Loftus et al., who have evaluated the material properties of BSA-based ERBs (also termed biopolymer-bound soil composites, BSCs) in depth [20,24-27].

The production of BSA in situ on a space mission would likely be problematic; either a cow would have to be transported along with the crew and their blood plasma periodically harvested — or the BSA could be produced recombinantly (i.e., synthetically) through a bioreactor [15]. If the latter option were to be employed, it would be more sensible to produce a protein with superior mechanical properties or otherwise greater utility than BSA, such as synthetic spider silk, squid ring teeth proteins, mussel adhesive proteins, or barnacle cement [15]. However, human-derived HSA has significant homology with bovine-derived BSA, and since humans would already be present on any crewed space flight, there would be no need to take additional animals such as cows onto the mission if the blood-plasma extraction method was to be employed. Therefore, we set out to investigate the material properties of HSA-based ERBs.

We employed a simple, custom-made setup for the fabrication of ERBs since complex, heavy equipment should ideally be avoided on a trip to Mars to minimize mission costs. It should therefore be highlighted that the use of more advanced fabrication techniques (e.g., hydraulic compression, vacuum-assisted resin infusion, etc.) would likely further improve material performance. Our fabrication method consisted of loosely packing approximately $2.4-3 \mathrm{~cm}^{3}$ of Lunar or Martian regolith simulant (LHS-1 and MGS-1, respectively) into a $5 \mathrm{~cm}^{3}$ disposable plastic syringe (Fig. 2.). Syringes were employed due to their consistent crosssectional surface area $\left(1.15 \mathrm{~cm}^{2}\right)$, ability to connect with appropriate tubing for liquid binder infusion, and for their low-cost disposable nature. After regolith packing, a solution of HSA in water could be infused with the regolith by injection from another syringe.

The wet composites were weighed before and after infusion to allow the determination of the binder mass ratio. The wet composites were then heated to $65^{\circ} \mathrm{C}$ to accelerate dehydration, with occasional removal of the supporting syringe tube to facilitate the escape of moisture. It should be noted that the methods used by Loftus et al. to produce BSAbased ERBs differed from our technique by employing a vacuumassisted resin infusion method (VARIM) and room-temperature desiccation. [20].

\subsection{Relationship between HSA-regolith mass ratio and ERB compressive strength}

The compressive strength of aggregate-bound composite materials such as concrete or ERBs depends on numerous factors, such as binder-toaggregate mass ratio, aggregate size and shape distribution, void size, and chemical composition [24,36,37]. Given the numerous challenges and constraints associated with extraterrestrial construction, pretreatment of extraterrestrial regolith should ideally be kept to a minimum. For instance, although Lunar and Martian regolith could be processed and refined to optimize properties such as chemical composition and particle size distribution, to do so in situ would necessitate processing equipment that would add to the mass, cost, and complexity of a mission. Therefore, in this study, we employed Lunar and Martian regolith simulants (LHS-1 and MGS-1, respectively) without additional processing. The precise composition of these simulants is given in the SI. One significant factor that could be easily and reliably controlled was the binder-to-aggregate mass ratio - which could be governed by initial protein solution concentration. [24].

This factor was, therefore, investigated by fabricating a number of HSA-ERBs with protein concentrations ranging between 15 and $37.5 \mathrm{wt}$ $\%$. A higher concentration of $40 \mathrm{wt} \%$ was attempted, but the solution was too viscous to infuse into the regolith. The binder-to-regolith mass ratio was determined by subtracting the dry regolith mass from the wet composite mass to determine the mass of HSA solution added, from which the dry mass of HSA could be determined based on the concentration of the solution. Compressive strength and stiffness (elastic modulus) were determined through uniaxial compression testing following ASTM guidelines (see Section 2 for details), with the data summarized in Table 2.

The data show a positive correlation between HSA concentration and calculated binder content (Fig. 3a). The data also show a clear positive correlation between HSA concentration and ultimate compressive strength (UCS) up to a concentration of $35 \mathrm{wt} \%$ (Fig. 3b), likely due to a generally increasing binder-to-mass ratio improving adhesion between particles. For both LHS-1 and MGS-1, the UCS dropped at the higher HSA concentration of $37.5 \mathrm{wt} \%$ - this was attributed to the higher viscosity of the solution, likely impeding impregnation into the smallest cavities and pores. A similar trend was also observed for the stiffness (i.e. the elastic modulus under compression) of the materials, which peaked at $30 \mathrm{wt} \%$ HSA (Fig. 3c and d). Visible light images of representative samples before and after compression tests, along with typical stressstrain profiles, are shown in Fig. S1. Our previous study on BSA-based adhesives conducted a rheology study on aqueous BSA solutions, which found that viscoelastic properties, including storage modulus, elastic modulus, and dynamic viscosity, all increased dramatically between a concentration of 30 and $40 \mathrm{wt} \%$ and were detrimental to adhesion [17].

\section{Table 2}

HSA-ERBs prepared with different HSA protein concentrations: summary of binder-to-regolith mass ratio, compressive strength, and elastic modulus. The number in parenthesis indicates the number of samples tested.

\begin{tabular}{lllll}
\hline $\begin{array}{l}\text { Regolith } \\
\text { type }\end{array}$ & $\begin{array}{l}\text { HSA } \\
\text { conc. } \\
\text { (wt. \%) }\end{array}$ & $\begin{array}{l}\text { Binder-to- } \\
\text { regolith } \\
\text { mass ratio (\%) }\end{array}$ & UCS (MPa) & $\begin{array}{l}\text { Elastic } \\
\text { modulus } \\
\text { (MPa) }\end{array}$ \\
\hline MGS-1 & 15 & $3.1 \pm 0.1$ & $1.9 \pm 0.3(5)$ & $431 \pm 111.8$ \\
MGS-1 & 20 & $5.4 \pm 0.1$ & $3.4 \pm 0.4(6)$ & $662 \pm 300$ \\
MGS-1 & 25 & $5.8 \pm 0.2$ & $5.8 \pm 1.5(6)$ & $541 \pm 224$ \\
MGS-1 & 30 & $8.8 \pm 0.3$ & $6.6 \pm 1.8(6)$ & $1257 \pm 390$ \\
MGS-1 & 35 & $8.1 \pm 0.3$ & $9.3 \pm 1.2(6)$ & $968 \pm 390$ \\
MGS-1 & 37.5 & $8.6 \pm 0.3$ & $6.4 \pm 1.2(6)$ & $905 \pm 343$ \\
LHS-1 & 15 & $3.7 \pm 0.2$ & $6.1 \pm 1.7(5)$ & $236 \pm 94$ \\
LHS-1 & 20 & $5.4 \pm 0.4$ & $9.4 \pm 1.1(6)$ & $540 \pm 158$ \\
LHS-1 & 25 & $6.1 \pm 0.1$ & $10.5 \pm 3.0(6)$ & $1096 \pm 474$ \\
LHS-1 & 30 & $8.0 \pm 0.3$ & $12.3 \pm 2.2(6)$ & $1673 \pm 890$ \\
LHS-1 & 35 & $8.6 \pm 0.3$ & $25.0 \pm 3.1(5)$ & $1618 \pm 479$ \\
LHS-1 & 37.5 & $10.8 \pm 3$ & $17.7 \pm 6.8(6)$ & $1568 \pm 578$ \\
\hline
\end{tabular}



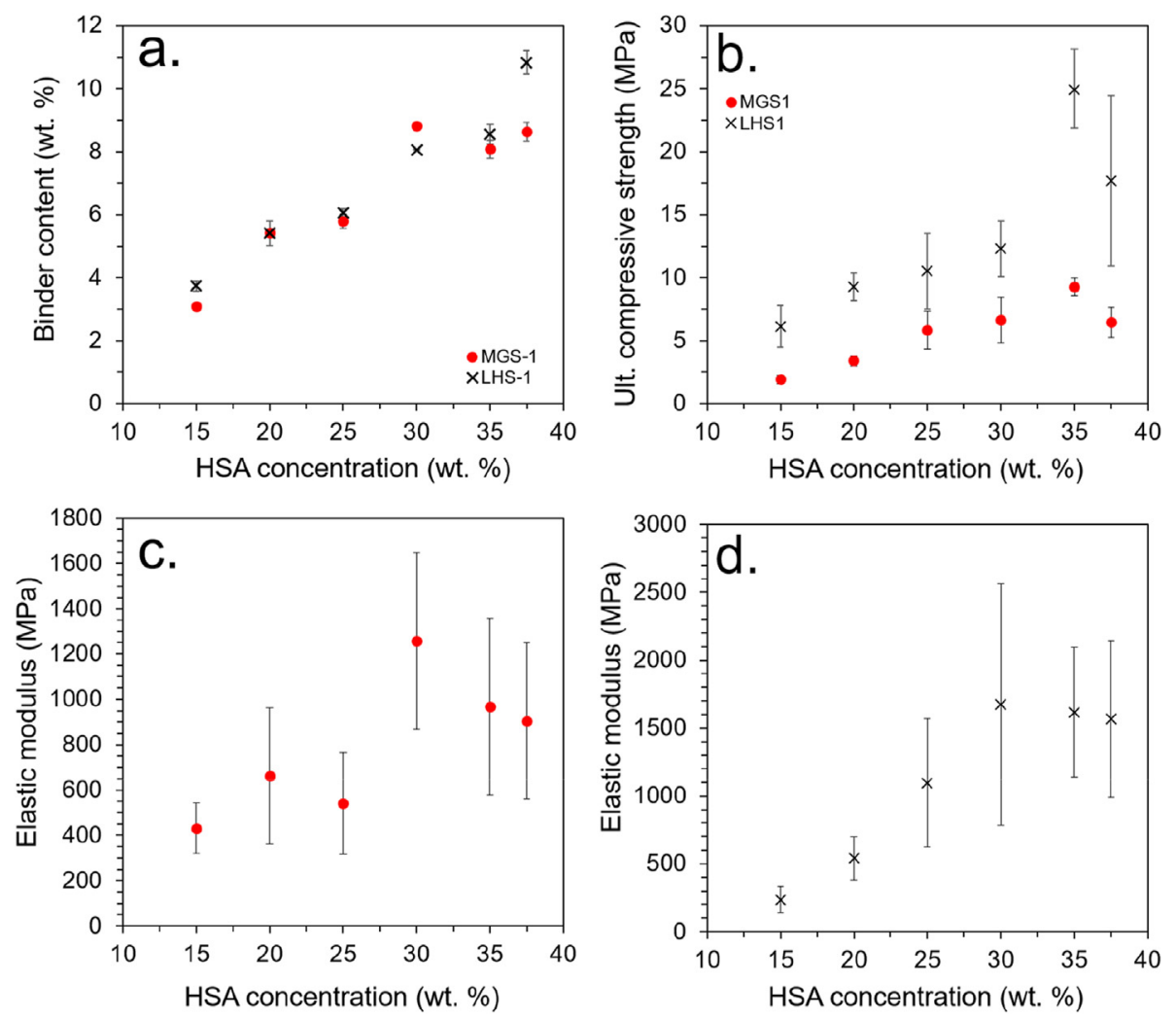

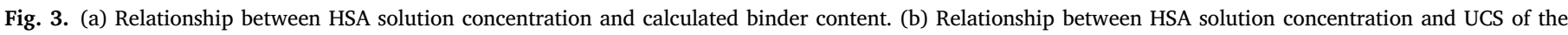
ERBs. (c) Relationship between elastic modulus under compression and HSA solution concentration for MGS-1 and (d) for LHS-1.

LHS-1 displayed consistently higher UCSs than MGS-1, which was primarily attributed to the physical properties of the aggregate particles [7]. LHS-1 is significantly coarser than MGS-1, which is an extremely fine powder. Coarser particles facilitate a more even distribution of stresses within aggregate-based composite materials, which corresponds to a higher toleration of compressive forces. Optimization of MGS-1 particle size distribution (e.g., through sieving) would likely improve the compressive strength of the resulting ERBs, but to do so in situ would increase the mission complexity and cost.

In order to benchmark and compare against the previous findings of Loftus et al. [20,24-27], BSA-based ERBs employing a BSA concentration of $30 \mathrm{wt} \%$ were also fabricated and tested. These displayed notably superior performance to HSA-based ERBs at the same concentration, with the LHS-1 based BSA-ERBs having a UCS of $19.5 \pm 1.7 \mathrm{MPa}$ and the MGS-1 based BSA-ERBs having a UCS of $12.0 \pm 1.3 \mathrm{MPa}$. We note that BSA is significantly cheaper than HSA and so could be a useful model compound for future studies. Finally, we also tested a ready-mixed brick mortar (purchased from Wickes ${ }^{\circledR}$ Stockport, UK) as a further benchmark, where the UCS from six replicate measurements was found to be $6.1 \pm 1.7 \mathrm{MPa}$ - significantly lower than the ERBs.

\subsection{Probing the bonding mechanism}

Cement and other high-strength bonding materials such as epoxy resin and cyanoacrylate adhesives generally rely on the formation of covalently bonded crosslinked networks (e.g., silicate networks in cement) to harden and bind aggregate and other materials together. It is noteworthy then that the HSA employed in this study, as well as other protein-based binders in previous literature reports, should display such high bonding strengths without any apparent covalent crosslinking, relying exclusively on physical interactions for cohesion and adhesion $[14,17]$. The mechanism behind such non-covalent protein bonding is complex and has yet to be fully resolved, but likely involves a mixture of interactions, including entanglement, ionic-, hydrophilic-, and hydrophobic bonding [14]. We recently proposed a mechanism based on the dehydration-induced reorganization of protein secondary structure from a relatively $\alpha$-helix rich conformation to a densely hydrogen-bonded supramolecular $\beta$-sheet network, supported by circular dichroism (CD) study [17]. This mechanism is analogous to the phase transformation of native spider silk from a concentrated liquid-crystalline solution (in the ampulla) to a $\beta$-sheet rich network (through the spinning duct), where extensive intermolecular hydrogen-bonding interactions contribute to the exceptional strength and toughness of spider silk [32,34,38,39]. Our previous work demonstrated remarkably similar changes to protein secondary structure when comparing BSA with recombinant spider silk over the course of adhesion, suggesting a similar underlying mechanism [17].

Given the significant structural and functional homology between BSA and HSA [40,41], we hypothesized that an analogous bonding mechanism was occurring for HSA, as we had previously shown for BSA. For testing this hypothesis, a CD was employed on a thin film of $5 \mathrm{wt} \%$ HSA laminated between two quartz substrates, with measurements taken every hour over a $20 \mathrm{~h}$ period at $20^{\circ} \mathrm{C}$ (see Section 2 for details). Concentrations above $5 \mathrm{wt} \%$ could not be employed as this would saturate the UV detector. After the $20 \mathrm{~h}$ period, the quartz substrates were strongly bonded and had to be soaked in water overnight to induce de-bonding. The obtained CD spectra are presented in Fig. 4a, with a breakdown of the secondary structural assignment given in Fig. $4 \mathrm{~b}$. A full breakdown of the secondary structure along with values for normalized root-mean-square deviation (NRMSD) to indicate the quality of data fitting is given in Table S2. The data show a clear change in the secondary structure from being initially relatively $\alpha$-helix rich $(70.3 \%)$ and $\beta$-sheet poor $(8.9 \%)$ with a low proportion of disordered structure $(21.0 \%)$ to having significantly less $\alpha$-helix content $(15.0 \%)$ but a higher content of $\beta$-sheets (37.3\%) and disordered (47.7\%) secondary structure after the $20 \mathrm{~h}$ adhesion period. These data support our hypothesis that the 

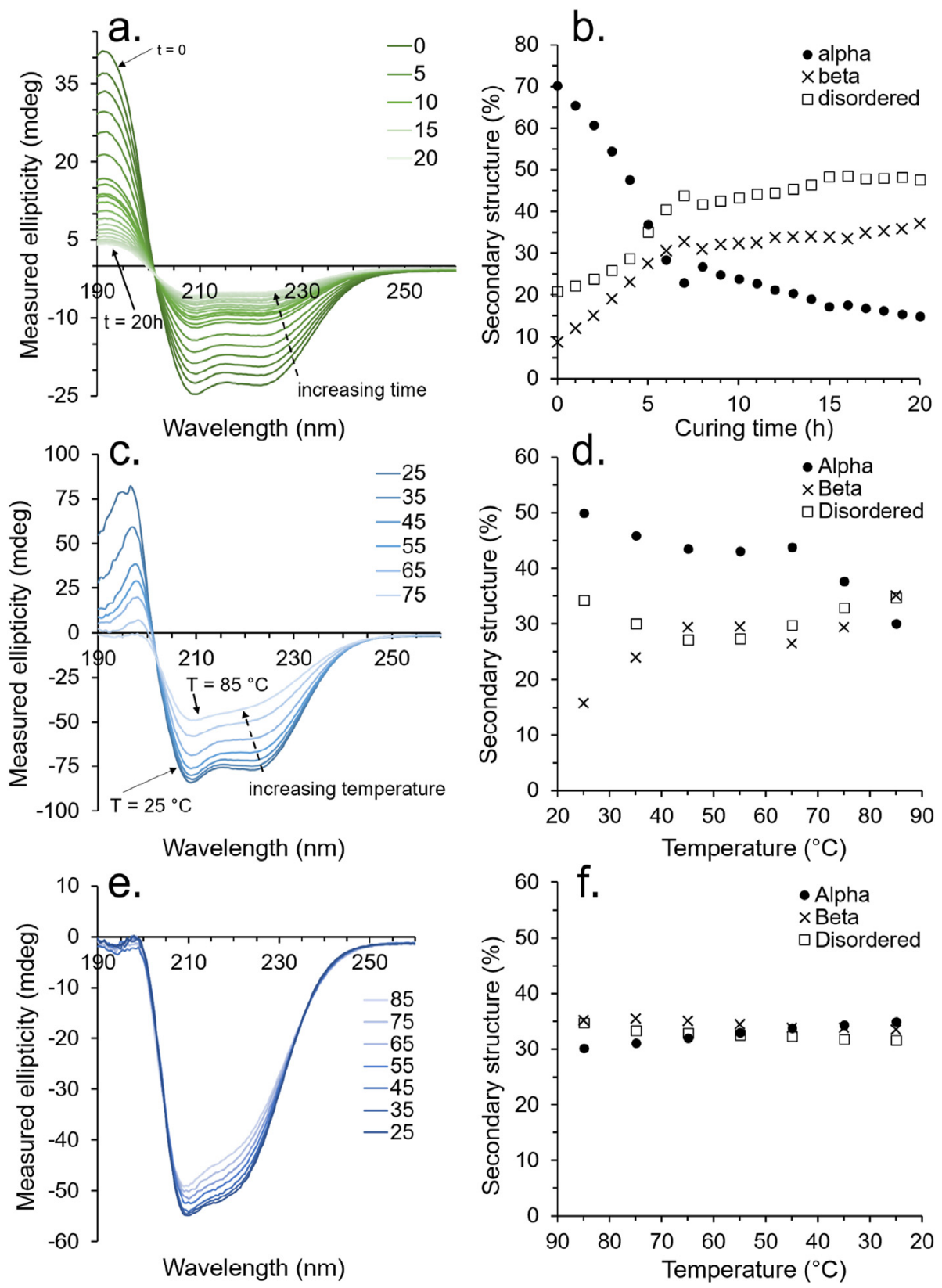

Fig. 4. (a) CD spectra of a $5 \mathrm{wt} \% \mathrm{HSA}$ solution laminated between two quartz substrates over a $20 \mathrm{~h}$ period with (b) corresponding changes to secondary structure. (c) $\mathrm{CD}$ spectra of a $0.1 \mathrm{wt} \% \mathrm{HSA}$ solution from $25^{\circ} \mathrm{C}$ to $85{ }^{\circ} \mathrm{C}$ with (d) corresponding changes to secondary structure. (e) $\mathrm{CD}$ spectra of the $0.1 \mathrm{wt} \% \mathrm{HSA}$ solution from $85^{\circ} \mathrm{C}$ to $25^{\circ} \mathrm{C}$ with (f) corresponding changes to secondary structure.

bonding mechanism is driven by a dehydration-induced change in protein secondary structure analogous to BSA and spider silk [17]. Further evidence for a glass-like transition state during the desiccation of BSA has also been published by G. Brownsey et al. [42] Interestingly, they suggest that at high concentrations BSA behaves like a colloidal suspension of globules - which is again analogous to how native spider silk behaves when stored as a high concentration liquid in the ampulla [32,38].

The thermal stability of HSA in the solution was also probed by CD spectroscopy. Here, a $0.4 \mathrm{wt} \%$ solution of HSA in water was aliquoted into a quartz cuvette with a path length of $0.1 \mathrm{~mm}$. Again, higher concentrations could not be employed due to the saturation of the detector. $\mathrm{CD}$ measurements were taken at $10^{\circ} \mathrm{C}$ intervals beginning at $25^{\circ} \mathrm{C}$ up to $85^{\circ} \mathrm{C}$ (Fig. 4c and d) before back down to $25^{\circ} \mathrm{C}$ (Fig. 4e and f). The data show irreversible thermal denaturation of the HSA over the course of this heat treatment, occurring primarily between 65 and $75{ }^{\circ} \mathrm{C}$, which is in line with the literature [43]. Interestingly, the degree of secondary structural change was far less pronounced than was observed for the dehydration-induced bonding - with total $\alpha$-helix, $\beta$-sheet, and disordered secondary structure content all stabilizing in the region of $31-35 \%$. A full breakdown of the secondary structure along with NRMSD is given in Table S3.

To investigate whether the process of denaturation was an important part of the bonding mechanism or whether denatured HSA would bond as effectively as non-denatured HSA, we intended to denature HSA prior to infusion with the regolith aggregate. This was, however, not possible since the thermally denatured HSA formed a gelatinous material that could not be infused into the aggregate. We conclude, therefore, that only non-denatured HSA can be employed due to appropriate viscoelastic properties - but it remains unclear if the process of denaturation is critical to the bonding mechanism.

FE-SEM was employed to visualize the microscopic bonding mechanism between HSA and aggregate particles (Fig. S3). The images appear 
to show ligament-like ties between particles, which is in concordance with the findings of Roedel et al. [20,25].

\subsection{Incorporating urea into the formulation}

Human urine will be produced in a significant quantity (0.8-2 L per crew member per day) on any long-term crewed space mission and will likely be fully recycled to maximize utility and avoid waste [31]. Aside from the recovery of water, which comprises $91-96 \%$ of urine [44], other metabolic wastes, including inorganic salts, urea, uric acid, and other organic compounds, will be recovered and recycled. Along with other human excreta, the primary use of processed urine will likely be as a fertilizer for plant growth $[45,46]$.

The average person produces approximately $59 \mathrm{~g}$ of total urine solids per day, of which urea is the largest component at over $50 \%$ of the total [44]. Urea is also present in human sweat and tears [47,48], also predicted to be in high abundance on any Martian mission. Its relatively high abundance means that, ideally, urea should be employed for higher value applications than purely as a fertilizer, especially since atmospheric Martian $\mathrm{N}_{2}$ could be biologically fixed to make up for any shortfall in a closed human — plant nitrogen cycle [49].

Concentrated urea is a powerful protein denaturant and is routinely used in biological laboratories for this purpose [50]. Urea also forms strong hydrogen-bonded networks with itself and other compatible molecules [51]. Given that the HSA adhesion mechanism was attributed to protein denaturation (unfolding) and reorganization into a strongly hydrogen-bonded $\beta$-sheet rich conformation, we thought it would be interesting to investigate the effect of urea incorporation into the HSA formulation.

To do this, we employed solutions of urea in water as the HSA solvent rather than pure water. Relatively high HSA concentrations of 30 and $35 \mathrm{wt} \%$ were investigated since these had previously displayed the highest ERB compressive strengths (see section 3.2). Urea solutions of $1 \mathrm{M}, 2 \mathrm{M}$, and $3 \mathrm{M}$ concentrations were investigated to determine any trends with increasing concentration. A higher urea concentration of $4 \mathrm{M}$ was also attempted, but this caused the HSA solutions to gel — likely due to a combination of partial protein denaturation and supersaturation. The combination of $35 \mathrm{wt} \%$ HSA and $3 \mathrm{M}$ urea was too viscous for infusion with MGS-1. The marginally higher density of urea solutions compared to water (e.g., $1.03 \mathrm{~g} \mathrm{~mL}^{-1}$ for $3 \mathrm{M}$ urea) were ignored and taken to be equal to the water in order to keep other factors (e.g. sample preparation procedure) consistent.

A summary of the materials produced, along with their compressive strength and stiffness (elastic modulus), is given in Table 3. The UCSs of the materials were found to increase significantly with the incorporation of urea. For MGS-1 with 30 wt $\%$ HSA, the UCS increased by $179 \%$ with the use of $3 \mathrm{M}$ urea compared to pure water. For MGS-1 with $35 \mathrm{wt} \%$ HSA, the UCS increased by $112 \%$ when $2 \mathrm{M}$ urea was employed compared to pure water. For LHS- 1 with $30 \mathrm{wt} \%$ HSA, the UCS increased by $324 \%$ when $3 \mathrm{M}$ urea was employed compared to pure water - and by $149 \%$ for the HSA $35 \mathrm{wt} \%$ formulation with $2 \mathrm{M}$ urea compared to water. For the $30 \mathrm{wt} \%$ HSA formulations with urea, the increase in compressive strength correlated well with increasing urea concentration (Fig. 5a and b). The trend was less pronounced with $35 \mathrm{wt} \%$ HSA, which may have been due to the relatively high viscosity of the solutions impeding infusion, resulting in voids that weakened the composites. Representative stress-strain curves for EBRs employing $30 \mathrm{wt} \% \mathrm{HSA}$ and $3 \mathrm{M}$ urea are given in Fig. $5 \mathrm{c}$ and $\mathrm{d}$.

We hypothesize three primary mechanisms to account for the increase in USS from the incorporation of urea, namely: (1) that urea facilitates the unfolding of the HSA from an $\alpha$-helix rich globular structure to the densely hydrogen-bonded $\beta$-sheet structure, (2) that urea promotes intramolecular hydrogen bonding between proteins and aggregate particles, and (3) that urea crystallizes out upon dehydration providing additional aggregate particles for the HSA to bind to. To investigate the proposed hypothesis, CD was employed on a HSA 5\% formulation
Table 3

Summary of HSA-ERBs prepared with 30 and $35 \mathrm{wt} \%$ HSA and various urea concentrations, including compressive strength and elastic modulus. The number in parenthesis indicates the number of samples tested.

\begin{tabular}{lllll}
\hline $\begin{array}{l}\text { Regolith } \\
\text { type }\end{array}$ & $\begin{array}{l}\text { HSA } \\
\text { conc. } \\
\text { (wt. \%) }\end{array}$ & $\begin{array}{l}\text { Urea } \\
\text { conc. } \\
(\mathrm{M})\end{array}$ & UCS (MPa) & $\begin{array}{l}\text { Elastic } \\
\text { modulus } \\
\text { (MPa) }\end{array}$ \\
\hline MGS-1 & 30 & 0 & $6.6 \pm 1.8(6)$ & $1257 \pm 390$ \\
MGS-1 & 30 & 1 & $7.2 \pm 1.5(4)$ & $532 \pm 167$ \\
MGS-1 & 30 & 2 & $9.2 \pm 2.1(4)$ & $1586 \pm 517$ \\
MGS-1 & 30 & 3 & $11.9 \pm 1.3(4)$ & $939 \pm 508$ \\
MGS-1 & 35 & 0 & $9.3 \pm 2.1(6)$ & $968 \pm 390$ \\
MGS-1 & 35 & 1 & $8.8 \pm 2.2(4)$ & $1143 \pm 593$ \\
MGS-1 & 35 & 2 & $10.4 \pm 2.3(3)$ & $1540 \pm 893$ \\
MGS-1 & 35 & 3 & Too viscous & Too viscous \\
LHS-1 & 30 & 0 & $12.3 \pm 2.2(6)$ & $1673 \pm 890$ \\
LHS-1 & 30 & 1 & $16.8 \pm 3.5(4)$ & $998 \pm 337$ \\
LHS-1 & 30 & 2 & $31.2 \pm 5.8(4)$ & $1916 \pm 544$ \\
LHS-1 & 30 & 3 & $39.7 \pm 3.9(4)$ & $1746 \pm 354$ \\
LHS-1 & 35 & 0 & $25.0 \pm 3.1(6)$ & $1618 \pm 479$ \\
LHS-1 & 35 & 1 & $23.7 \pm 3.3(4)$ & $4508 \pm 3616$ \\
LHS-1 & 35 & 2 & $37.4 \pm 2.2(4)$ & $1823 \pm 627$ \\
LHS-1 & 35 & 3 & $29.5 \pm 1.3(4)$ & $1239 \pm 122$ \\
\hline
\end{tabular}

dissolved in $3 \mathrm{M}$ urea in an analogous manner to the previous $\mathrm{CD}$ measurements. This again revealed significant changes to the $\mathrm{CD}$ profile over the course of the $24 \mathrm{~h}$ bonding period (Fig. S4); however, the secondary structure could not be determined due to poor peak fitting - likely due to interference from the presence of urea. A more in-depth study would therefore be needed to unpick the mechanism.

In addition to significantly increasing the compressive strength of the ERBs, the incorporation of urea would also increase the density and lightatom content of the materials. This would be expected to improve the radiation shielding potential of the ERBs - particularly neutrons generated by cosmic rays [7].

\subsection{Investigating recombinant spider silk ERBs}

Recombinant protein production has been employed for decades and is well known for the production of synthetic human insulin [52]. Recombinant proteins have also been explored for materials science applications, most notably the production of synthetic spider silk for its impressive material properties [15,34,53-55]. The versatile bioproduction of materials, fuels, fine chemicals, pharmaceuticals, and food on the surface of Mars could result in significant reductions in payload mass (between 26 and $85 \%$ ) compared to conventional approaches [28, 30], reducing mission cost. However, significant improvements in bioreactor efficiency, reliability, and recyclability of metabolic wastes will be needed before significant bioproduction on Mars will be viable [31], although significant advances in terrestrial bioproduction are expected in the near future [56,57].

As depicted in Fig. 1, HSA-based ERBs could eventually be supplemented or surpassed by recombinant protein production from versatile bioreactors, which may have a variety of other uses [28,30]. Although HSA can be produced recombinantly, proteins with superior properties or other beneficial features may as well be produced instead. For example, recombinant spider silk due to its exceptional mechanical strength and toughness $[14,39,53]$, or squid ring teeth proteins for self-healing properties [58,59], among others [15].

To test whether, in principle, recombinant spider silk could be employed as a binder for extraterrestrial regolith - we produced and concentrated a small volume and fabricated ERBs with LHS-1 and MGS-1. Since the production of significant quantities of concentrated recombinant spider silk is difficult (the protein tends to spontaneously aggregate upon concentration), only a small volume of about $200 \mu \mathrm{L}$ could be produced (average yield was $50 \mathrm{mg} \mathrm{L}^{-1}$ ). This was only enough to produce a single thin disk of about $2 \mathrm{~mm}$ in thickness and $13 \mathrm{~mm}$ in diameter for both LHS-1 and MGS-1 (Fig. 6a and b). This was not a suitable format 

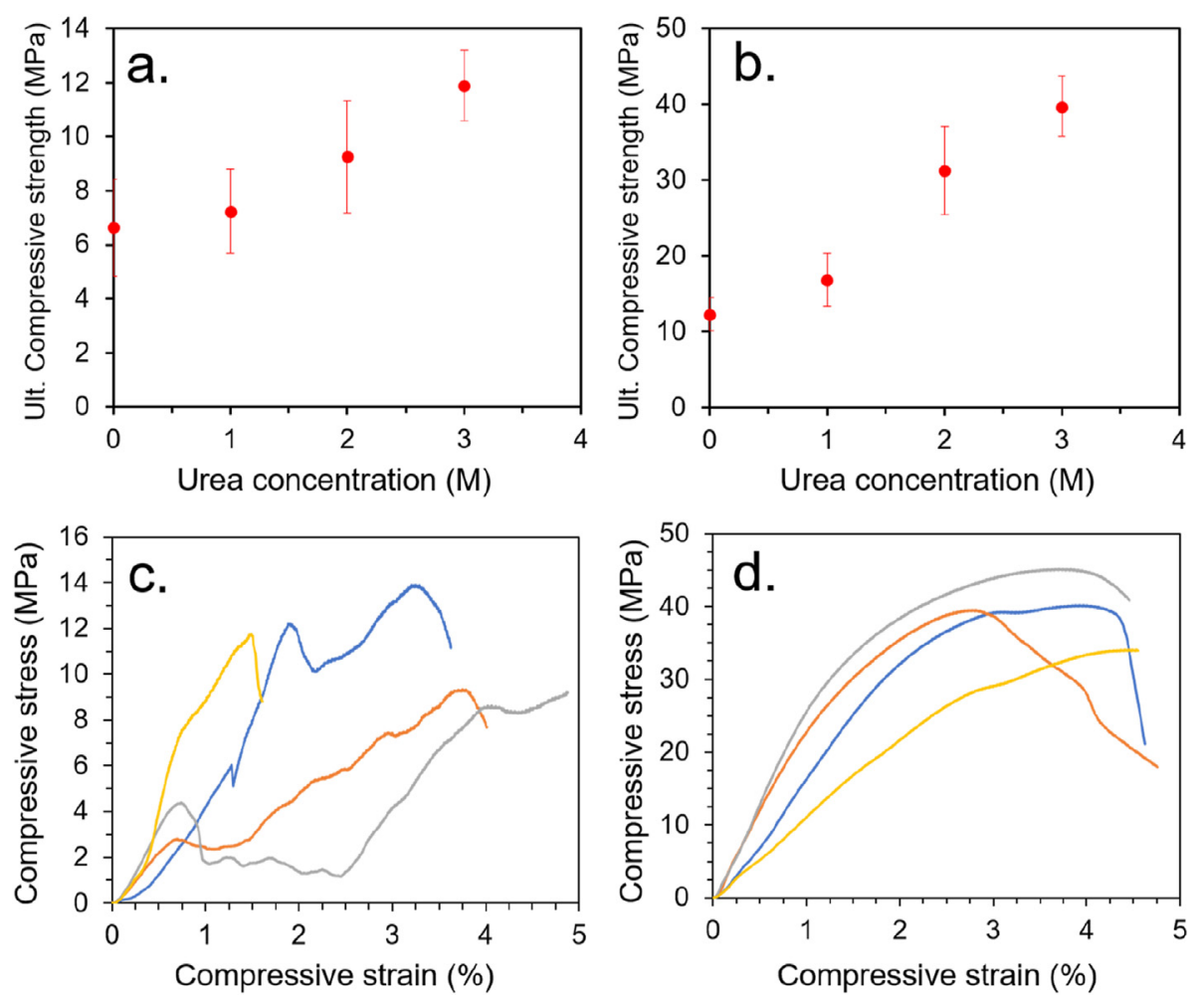

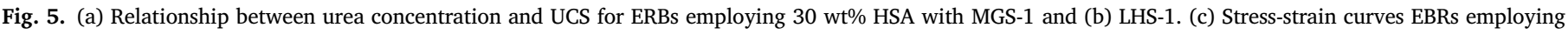
$30 \mathrm{wt} \%$ HSA and $3 \mathrm{M}$ urea with MGS-1 and (d) LHS-1.

for compression tests where much larger cylinders and several replicate samples are needed; therefore, we were not able to determine the mechanical properties in comparison to HSA or BSA. The experiment did, however, demonstrate that recombinant spider silk could, in principle, be employed to produce ERBs without any additional crosslinking agents. FE-SEM images also revealed similar ligament-like ties between the particles, as was observed with HSA (Fig. 6c-f).

\subsection{Demonstrating the potential of HSA-ERBs for 3D-printing}

Housing construction on Earth typically relies on a variety of materials with complex supply chains and laborious manual assembly by various specialists. This terrestrial approach is not viable in early Lunar or Martian colonies, which will require radically different construction techniques. Additive manufacturing (3D-printing) is regarded as a promising technique for extraterrestrial habitat construction since it can produce complex shapes and geometries, including hollow parts with internal support structures [60-62]. NASA's Space Technology Mission Directorate recently concluded a Centennial Challenge competition with a focus on developing technologies for 3D-printed habitats, awarding over $\$ 2$ million in total [5].

Given the interest in 3D-printing for extraterrestrial habitat construction, we conducted a simple scoping experiment to determine if HSA-ERBs could feasibly be 3D-printed. Lacking appropriate 3D-printing equipment, we instead manually extruded a mixture of MGS-1 and HSA $15 \mathrm{wt} \%$ (3:1 mass ratio) out of a disposable $5 \mathrm{~mL}$ syringe in an approximate $25 \times 25 \mathrm{~mm}$ square (wall thickness ca. $3 \mathrm{~mm}$ ) onto an aluminum plate maintained at $65^{\circ} \mathrm{C}$. The HSA concentration of $15 \mathrm{wt} \%$ was selected due to its relatively low viscosity allowing for easier extrusion. After a 1-2 min resting period to allow for dehydration-induced hardening, further layers were added until a height of approximately $2 \mathrm{~cm}$ was achieved. The 3D-printed HSA-ERB was then left at $65{ }^{\circ} \mathrm{C}$ overnight to ensure thorough dehydration. Fig. 7a shows the completed 3D-printed construction after drying. The construction was subject to uniaxial compression until destruction to determine the strength of the construction (compression test set-up depicted in Fig. $7 \mathrm{~b}$ and c), where it sustained an ultimate compressive force of $600 \mathrm{~N}$ - which is equivalent to a mass of $61 \mathrm{~kg}$ under Earth's gravity, $162 \mathrm{~kg}$ on Mars or $370 \mathrm{~kg}$ on the moon (gravitational constants of $9.81,3.71$ and $1.62 \mathrm{~N} \mathrm{~kg}^{-1}$, respectively). The ultimate compressive strength of the construction was approximately 1.9 MPa but could potentially be improved with higher HSA concentrations and the incorporation of urea.

\subsection{Adhesive performance of HSA on glass}

Lunar and Martian regolith largely comprises silica $(\sim 50 \%)$ and alumina $(\sim 10 \%)$ meaning that the manufacture of glass-like ceramic materials would be possible through either sintering or melting appropriate ore or regolith $[2,7,63,64]$. The high energy cost of such processes (temperatures of $1200-1500{ }^{\circ} \mathrm{C}$ needed to melt regolith) may constrain the technique to the production of relatively small bricks, which would need to be further fused together by either heat, an adhesive, or a mortar for use as a construction material [7]. Although 3D-printing of regolith has been investigated, to date, the mechanical properties of the produced materials have been relatively low compared to other regolith binding methods, and significant equipment (i.e.. large mirrors) are needed [7]. The solar 3D-printing technique is also less feasible on the Martian surface than the lunar surface due to lower solar flux.

Here, we investigated the adhesive performance of a HSA-based solution on the glass to determine whether - in principle - HSA could be employed to adhere together glass-like materials such as sintered or melted regolith bricks. We have previously conducted an analogous investigation with BSA [17].

The results, presented in Table 4 along with a comparison of similar adhesives, found that HSA had an average ultimate shear strength (USS) of $5.2 \pm 1.8 \mathrm{MPa}$ based on seven replicate measurements (Fig. S5). As a direct comparison, a cyanoacrylate adhesive (Loctite ${ }^{\circledR}$ Superglue) was also tested under analogous conditions and had an average USS of 

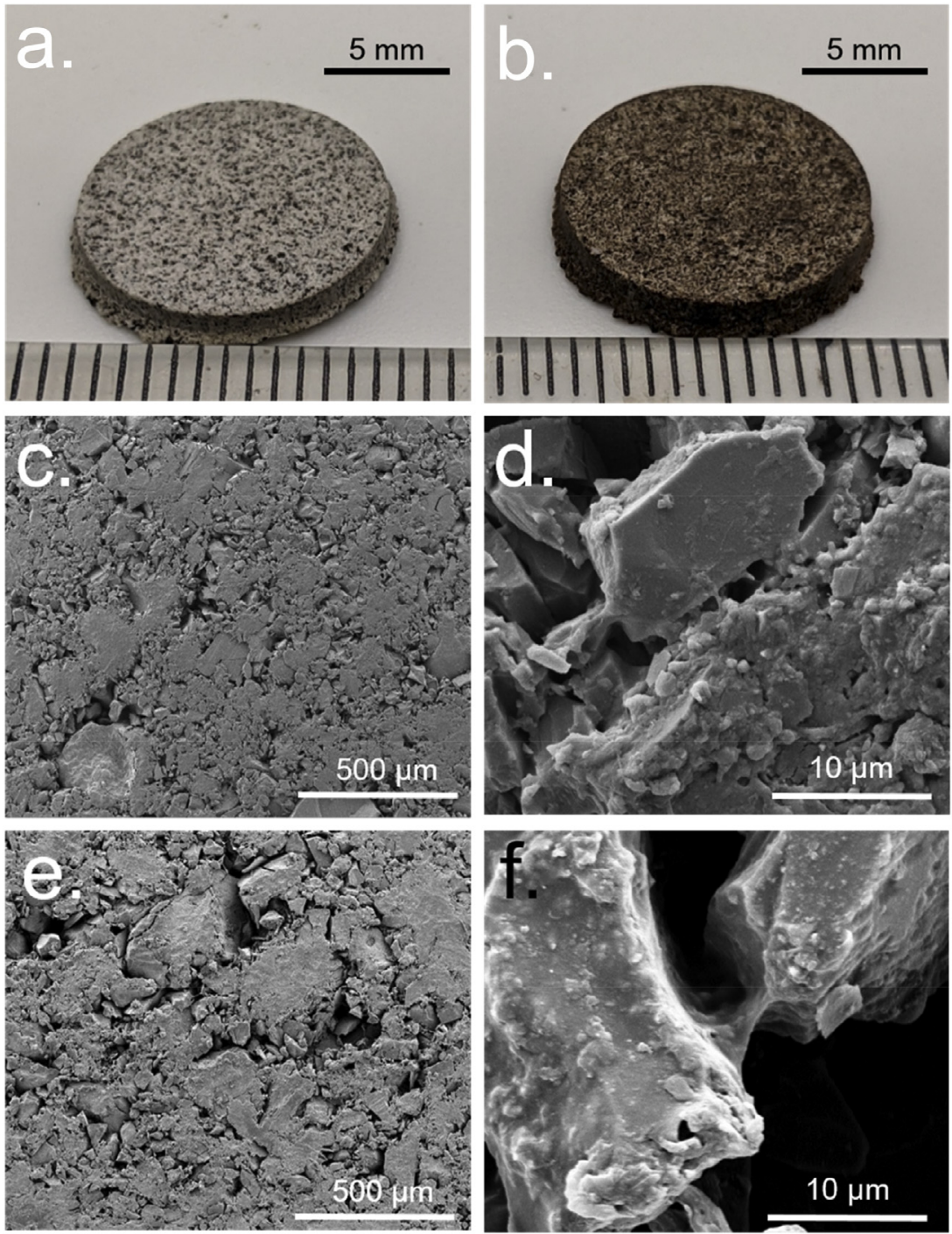

Fig. 6. Visible light images of recombinant spider silk-based ERBs: (a) LHS-1 and (b) MGS-1. FE-SEM images of recombinant spider silk-based ERBs: (c) LHS-1 $\times 100$ magnification, (d) LHS- $1 \times 5000$ magnification (e) MGS- $1 \times 100$ magnification, (f) MGS- $1 \times 5000$ magnification.
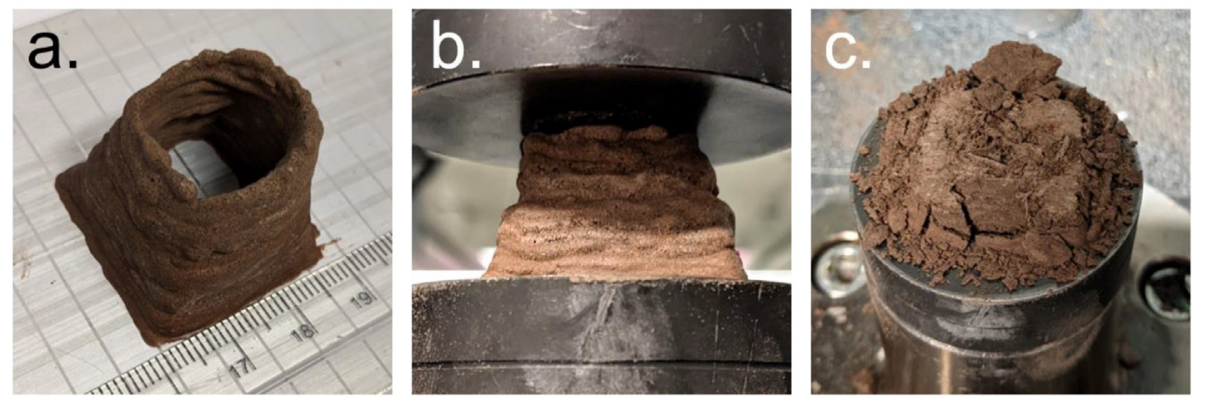

Fig. 7. Visible light images of the 3D-printed HSA-ERB based on MGS-1. (a) after fabrication, (b) during compression testing, and (c) after compression testing.

$3.3 \pm 1.2 \mathrm{MPa}$. Our previous study found that both BSA and recombinant spider silk had higher USS values at $8.53 \pm 1.96$ and $6.28 \pm 1.09 \mathrm{MPa}$, respectively. Given the relatively small volumes of protein solution needed to conduct adhesive tests via this method ( $5 \mu \mathrm{L}$ per sample), shear-lap adhesion tests such as these could be an efficient way to optimize formulations using difficult-to-produce recombinant proteins such as synthetic spider silk before scale-up to produce composite materials such as ERBs.

\section{Discussion}

The remarkably high compressive strength of HSA-ERBs — which could be fabricated with minimal ex situ components without any heavy, malfunction-prone in situ binder production equipment — certainly warrants further investigation. We note that there is significant scope for improvement of material properties, too, with many factors such as curing temperature, compacting, and method of binder infusion having 
Table 4

Summary of the USS of HSA and BSA-based adhesives, recombinant spider silkbased adhesives, and (for comparison) some commercial adhesives on glass and aluminum determined by single-lap-joint shear tests. The number in parentheses indicates the number of replicate measurements.

\begin{tabular}{|c|c|c|c|}
\hline Adhesive & Substrate & $\begin{array}{l}\text { Ultimate shear } \\
\text { stress (MPa) }\end{array}$ & Ref \\
\hline HSA (30 wt $\%)$ & Borosilicate glass & $5.2 \pm 1.8(7)$ & This work \\
\hline Loctite $®$ Superglue & Borosilicate glass & $3.3 \pm 1.2(3)$ & This work \\
\hline BSA (30 wt $\%)$ & Borosilicate glass & $8.53 \pm 1.96(8)$ & [17] \\
\hline $\begin{array}{l}\text { BSA-ascorbic acid } \\
\quad(10: 1,30 \% \mathrm{w} / \mathrm{v})\end{array}$ & Aluminum & $2.8 \pm 0.7$ & [65] \\
\hline $\begin{array}{l}\text { Spider silk } \\
\qquad(\mathrm{pH} 8,30 \mathrm{w} / \mathrm{v} \%)\end{array}$ & Borosilicate glass & $6.28 \pm 1.09(8)$ & [17] \\
\hline $\begin{array}{l}\text { Spider silk } \\
\qquad(12 \% \mathrm{w} / \mathrm{v})\end{array}$ & Aluminum & 1.16 & [14] \\
\hline Epoxy resin & Glass & 14.4 & [66] \\
\hline
\end{tabular}

yet to be optimized. A significant amount of formulation optimization could also improve properties, such as $\mathrm{pH}$ and ionic conditions, or the inclusion of other in vivo substances such as feces, human hair, mucus, or other bodily fluids into the formulation.

There is still a significant amount of uncertainty over the challenges associated with material processing for various proposed Martian binder technologies. In situ binders based on chemical and biochemical production will likely require significant downstream processing (e.g., purification, chemical modification, formulation, etc.), which will add extra complexity and risk of component failure. In contrast, the processing and use of HSA ought to be comparatively straightforward [18]. Fig. 8 shows a hypothetical life cycle process flow diagram depicting the important steps involved from raw materials to end-of-life, based on the sustainability assessment conducted by Loftus et al. [25] We note that HSA-ERBs should be fully recyclable at the end of life, either by dissolution and re-use of HSA as a binder - or recycling the organic matter for reclamation by the food production system (i.e. composting). Synthetic polymer/resin binders and Martian cement may be much more difficult to recycle at the end-of-life phase.
Even if HSA-ERBs turn out to be unviable for significant use on a Martian colony, understanding the potential uses and limitations of such materials could be critical in an emergency situation that requires flexibility and ingenuity to solve. The significant time delay between Earth and Mars, both in terms of logistical resupply ( $\sim 26$ months) and communication (up to $44 \mathrm{~min}$ ) [1], means that the ability for astronauts to devise solutions to novel threats and implement emergency repairs with the resources at hand will be critical to mission safety. The understanding that human blood plasma and urine, combined with regolith, can form a strong material could potentially solve a life-threatening emergency. As we have demonstrated, HSA-ERBs can also be 3D-printed using simple equipment (a syringe and $65{ }^{\circ} \mathrm{C}$ hot-plate) - which could be significant if a specific item, tool, or component needing a relatively high compressive strength needs to be produced in an emergency.

Finally, we note that there may be terrestrial applications from the pursuit of this technology. Concrete is, quite literally, a foundation material of the global economy and accounts for $8 \%$ of anthropogenic $\mathrm{CO}_{2}$ emissions [67]. These emissions are primarily from the thermal decomposition of calcium carbonate $\left(\mathrm{CaCO}_{3}\right)$ to calcium oxide $(\mathrm{CaO})-$ a primary component of cement. This chemical release of $\mathrm{CO}_{2}$, which accounts for over $50 \%$ of emissions, cannot be avoided through the use of renewable or nuclear energy sources, and thus, greener aggregate binders should be sought. The production of large quantities of biomanufactured proteins on earth has been a reality since synthetic insulin was mass-produced in 1982, and such proteins are now being commercially produced for various material applications. The application of structural proteins such as synthetic spider silk as an aggregate binder to replace cement could be feasible with future developments [25]; however, the extremely low cost and established nature of cement would make it difficult to displace without significant financial incentives. The use of naturally occurring plant-based biopolymers and bio-aggregates may be a more feasible and sustainable route forward [16]. A detailed discussion of additional practical considerations and a comparison between different extraterrestrial habitat construction technologies is presented the Supplementary Information and in the Supplementary Table S1.

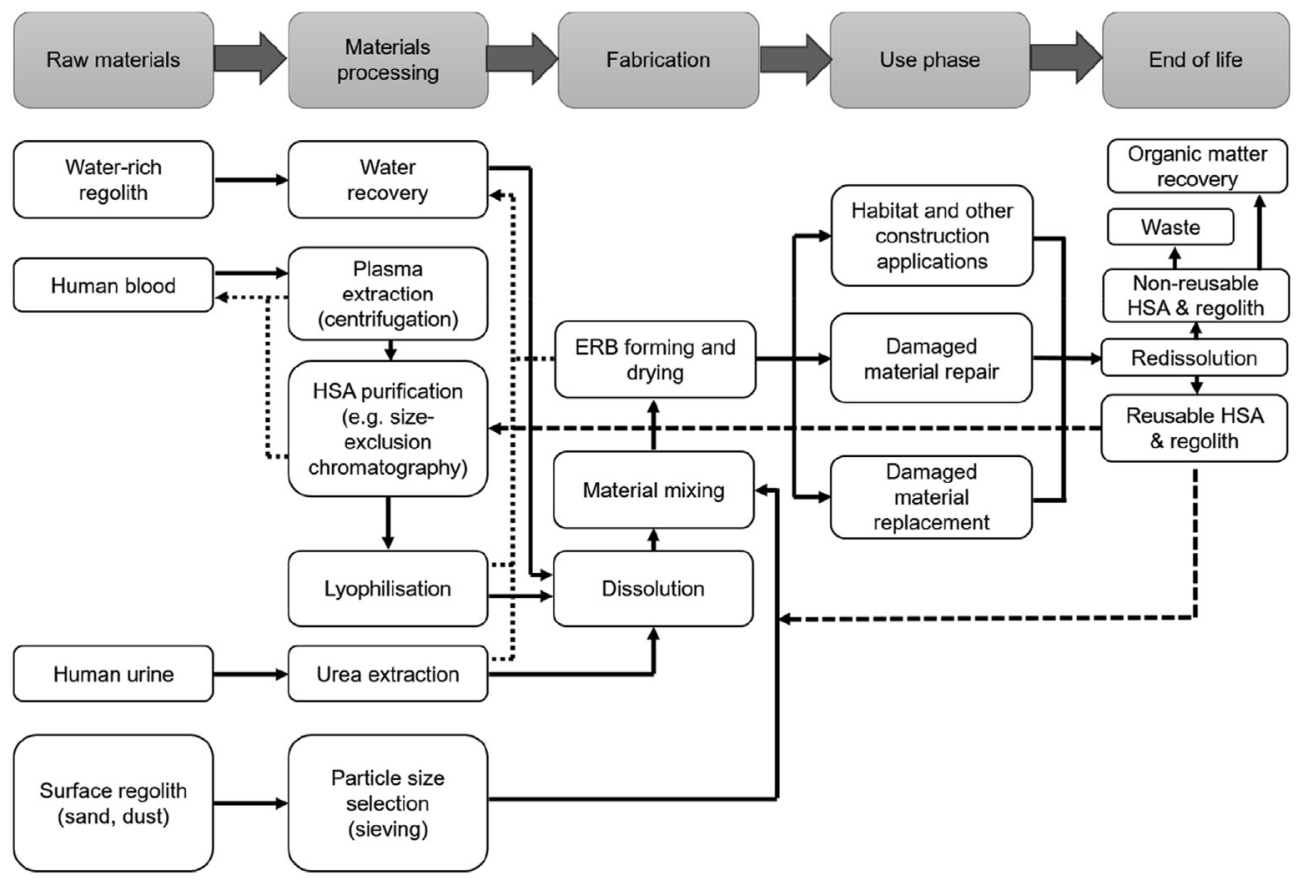

Fig. 8. Life-cycle process flow diagram for HSA/Urea-based ERBs. 


\section{Conclusions}

The sweat and blood of astronauts, metaphorically speaking, has always been a critical prerequisite of any crewed mission to Mars. In this study, we propose that their literal blood may have an important secondary application in addition to its primary purpose: as a binder for extraterrestrial regolith to produce concrete-like biocomposites (ERBs). With ultimate compressive strengths as high as $25.0 \mathrm{MPa}$ - or up to 39.7 MPa with the incorporation of urea - the produced ERBs can exceed the compressive strength of standard terrestrial concrete (typically 20-32 MPa) while having significant scope for further optimization.

Unlike other proposed in situ binder production technologies, this method circumvents the need for heavy and malfunction-prone binder production equipment (along with spare parts) needing to be delivered to the Martian surface. According to our calculations, a liter of human blood plasma contains enough HSA to produce about $300 \mathrm{~g}$ of ERB. If donated twice a week, each astronaut could produce about $2.5 \mathrm{~kg}$ of ERB per month - which is about the mass of a standard red clay brick. If employed as a mortar to bind together sandbags or bricks made from sintered or cast Martian regolith, our calculations suggest that each astronaut - over the course of a Martian mission - could produce enough additional habitat space to support another astronaut, potentially allowing the steady expansion of an early Martian colony.

Significant further investigation is still needed to determine the feasibility of the concept, particularly fatigue and durability evaluation under simulated Martian conditions (extreme thermal cycling, low pressures, high radiation, etc.) and the long-term health effects of continuous plasma donation in a reduced gravity environment. The quantity of HSA that could feasibly be extracted from astronauts without affecting their health would also need to be determined experimentally, and alternative options (e.g., use of plant-based proteins) should be explored. Despite this, we believe that HSA-ERBs could potentially have a significant role in a nascent Martian colony but will eventually be superseded by versatile bioreactors or other technologies as they mature.

\section{Credit author statement}

Aled Roberts: Conceptualization; Data curation; Formal analysis; Investigation; Methodology; Writing - original draft, Dominic Whittall: Investigation; Methodology; Writing - review and editing, Rainer Breitling: Project administration; Resources; Supervision; Writing - review and editing, Eriko Takano: Project administration; Resources; Supervision; Writing - review \& editing, Jonny Blaker: Project administration; Resources; Supervision; Writing - review and editing, Sam Hay: Project administration; Resources; Supervision; Writing - review and editing, Nigel Scrutton: Conceptualization; Funding acquisition; Project administration; Resources; Supervision; Writing - review and editing.

\section{Declaration of competing interest}

The authors declare that they have no known competing financial interests or personal relationships that could have appeared to influence the work reported in this paper.

\section{Acknowledgements}

This work was supported by the Future Biomanufacturing Research Hub (grant EP/S01778X/1), funded by the Engineering and Physical Sciences Research Council (EPSRC) and Biotechnology and Biological Sciences Research Council (BBSRC) as part of UK Research and Innovation. DRW was funded through European Union's Horizon 2020 Research and Innovation Program under Grant Agreement No. 720793 TOPCAPI-thoroughly Optimized Production Chassis for Advanced Pharmaceutical Ingredients. We acknowledge the University of Manchester Electron Microscope Centre and Mechanical Testing Facility for training and access to equipment and would like to thank Mr. Stuart Morse for his assistance and advice with mechanical testing.

\section{Appendix A. Supplementary data}

Supplementary data to this article can be found online at https:// doi.org/10.1016/j.mtbio.2021.100136.

\section{References}

[1] B.G. Drake, S.J. Hoffman, D.W. Beaty, Human exploration of mars, design reference architecture 5.0, in: IEEE Aerosp. Conf. Proc., IEEE, 2010, pp. 1-24, https:// doi.org/10.1109/AERO.2010.5446736.

[2] R.W. Moses, D.M. Bushnell, Frontier in-situ resource utilization for enabling sustained human presence on mars, NASA Sci. Tech. Inf. (2016) 1-22.

[3] J.R. Murphy, C.B. Leovy, J.E. Tillman, Observations of martian surface winds at the Viking Lander 1 site, J. Geophys. Res. 95 (1990) 14555-14576, https://doi.org/ 10.1029/jb095ib09p14555.

[4] M.P. Bodiford, M.R. Fiske, W. McGregor, R.D. Pope, In situ resource-based lunar and martian habitat structures development at NASA/MSFC, in: A Collect. Tech. Pap. - 1st Sp. Explor. Conf. Contin. Voyag. Discov., 2005, pp. 974-980, https:// doi.org/10.2514/6.2005-2704.

[5] NASA, NASA's Centennial Challenges, 3D-Printed Habitat Challenge, Https:// Www.Nasa.Gov., 2019 https://www.nasa.gov/directorates/spacetech/centennial _challenges/3DPHab/about.html. (Accessed 17 November 2020).

[6] Y. Reches, Concrete on mars: options, challenges, and solutions for binder-based construction on the red planet, Cement Concr. Compos. 104 (2019) 103349, https://doi.org/10.1016/j.cemconcomp.2019.103349.

[7] M.Z. Naser, Extraterrestrial construction materials, Prog. Mater. Sci. 105 (2019) 100577, https://doi.org/10.1016/j.pmatsci.2019.100577.

[8] M.Z. Naser, Space-native construction materials for earth-independent and sustainable infrastructure, Acta Astronaut. 155 (2019) 264-273, https://doi.org/ 10.1016/j.actaastro.2018.12.014.

[9] H. Lin, S. Gunasekaran, Cow blood adhesive: characterization of physicochemical and adhesion properties, Int. J. Adhesion Adhes. 30 (2010) 139-144, https:// doi.org/10.1016/j.ijadhadh.2009.10.003.

[10] K. Zhang, L. Rampazzi, M.P. Riccardi, A. Sansonetti, A. Grimoldi, Mortar mixes with oxblood: historical background, model sample recipes and properties, Adv. Geosci. 45 (2018) 19-24.

[11] P.A. Fay, Adhesive Bonding: Science, Technology and Applications, Woodhead Publishing, 2005, https://doi.org/10.1533/9781845690755.1.3.

[12] Y. Shen, A. Levin, A. Kamada, Z. Toprakcioglu, M. Rodriguez-Garcia, Y. Xu, T.P.J. Knowles, From protein building blocks to functional materials, ACS Nano 15 (2021) 5819-5837, https://doi.org/10.1021/acsnano.0c08510.

[13] R. Kumar, V. Choudhary, S. Mishra, I.K. Varma, B. Mattiason, Adhesives and plastics based on soy protein products, Ind. Crop. Prod. 16 (2002) 155-172, https:// doi.org/10.1016/S0926-6690(02)00007-9.

[14] T.I. Harris, D.A. Gaztambide, B.A. Day, C.L. Brock, A.L. Ruben, J.A. Jones, R.V. Lewis, Sticky situation: an investigation of robust aqueous-based recombinant spider silk protein coatings and adhesives, Biomacromolecules 17 (2016) 3761-3772, https://doi.org/10.1021/acs.biomac.6b01267.

[15] A.D. Roberts, W. Finnigan, E. Wolde-Michael, P. Kelly, J.J. Blaker, S. Hay, R. Breitling, E. Takano, N.S. Scrutton, Synthetic biology for fibers, adhesives, and active camouflage materials in protection and aerospace, MRS Commun. 9 (2019) 486-504, https://doi.org/10.1557/mrc.2019.35.

[16] V. Nozahic, S. Amziane, Environmental, economic and social context of agro-concretes, Bio. Aggreg. Build. Mater. (2013) 1-26, https://doi.org/10.1002/9781118576809.ch1.

[17] A.D. Roberts, W. Finnigan, P.P. Kelly, M. Faulkner, R. Breitling, E. Takano, N.S. Scrutton, J.J. Blaker, S. Hay, Non-covalent protein-based adhesives for transparent substrates-bovine serum albumin vs. recombinant spider silk, Mater. Today Bio. 7 (2020) 100068, https://doi.org/10.1016/j.mtbio.2020.100068.

[18] R. Raoufinia, A. Mota, N. Keyhanvar, F. Safari, S. Shamekhi, J. Abdolalizadeh, Overview of albumin and its purification methods, Adv. Pharmaceut. Bull. 6 (2016) 495-507, https://doi.org/10.15171/apb.2016.063.

[19] V.P. Grachev, A. Hoppe, D.I. Magrath, D.P. Thomas, D. Barrowcliffe, P. Brunko, N. Chariatte, J. Fischer, T. Golosova, H.J. Heiniger, A.G. Hildebrandt, F. Horaud, M. Koch, K. Komuro, M. Mozen, V. Ray, R.W. Reilly, M. Rodell, W.G. Van Aken, Q.H. Zhang, P. Corcoran, V. Grachev, C. Jersild, J. Koistinen, D. Magrath, Requirements for the collection, processing and quality control of blood, blood components and plasma derivatives (Requirements for Biological Substances No. 27, revised 1992), World Health Organ. Tech. Rep. Ser. 840 (1994) 34-98.

[20] H. Roedel, M.D. Lepech, D.J. Loftus, Protein-regolith composites for space construction, in: Earth Sp. 2014 Eng. Extrem. Environ. - Proc. 14th Bienn. Int. Conf. Eng. Sci. Constr. Oper. Challenging Environ., 2014, pp. 291-300, https://doi.org/ 10.1061/9780784479179.033.

[21] C.H. Simonds, Hot pressing of lunar soil and qualification for manned applications, in: Second Conf. Lunar Bases Sp. Act. 21st Century, 1988, pp. 90-101.

[22] M.I. Eren, M.R. Bebber, J.D. Norris, A. Perrone, A. Rutkoski, M. Wilson, M.A. Raghanti, Experimental replication shows knives manufactured from frozen human feces do not work, J. Archaeol. Sci. Rep. 27 (2019) 102002, https://doi.org/ 10.1016/j.jasrep.2019.102002.

[23] Ig® Nobel Prize Winners. https://www.improbable.com/ig-about/winners/, 2020. (Accessed 2 January 2021). 
[24] H. Roedel, I. Rosa, M.I. Allende, M.D. Lepech, D.J. Loftus, E.J. Garboczi, Prediction of ultimate compressive strength for biopolymer-bound soil composites (BSC) using sliding wingtip crack analysis, Eng. Fract. Mech. 218 (2019) 106570, https:// doi.org/10.1016/j.engfracmech.2019.106570.

[25] H. Roedel, I.R. Plata, M. Lepech, D. Loftus, Sustainability assessment of protein-soi composite materials for limited resource environments, J. Renew. Mater. 3 (2015) 183-194, https://doi.org/10.7569/JRM.2015.634107.

[26] I. Rosa, H. Roedel, M.D. Lepech, D.J. Loftus, Creation of statistically equivalent periodic unit cells for protein-bound soils, in: ASME Int. Mech. Eng. Congr. Expo. Proc., American Society of Mechanical Engineers, 2015, https://doi.org/10.1115/ IMECE2015-52029 p. V009T12A058.

[27] M.I. Allende, B.A. Davis, J.E. Miller, E.L. Christiansen, M.D. Lepech, D.J. Loftus, Hypervelocity impact performance of biopolymer-bound soil composites for space construction, J. Aero. Eng. 33 (2020), 04020001, https://doi.org/10.1061/(asce) as.1943-5525.0001110.

[28] A.A. Menezes, M.G. Montague, J. Cumbers, J.A. Hogan, A.P. Arkin, Grand challenges in space synthetic biology, J. R. Soc. Interface 12 (2015) 20150803 , https://doi.org/10.1098/rsif.2015.0803.

[29] S. Zschokke, S. Countryman, P.E. Cushing, Spiders in space-orb-web-related behaviour in zero gravity, Sci. Nat. 108 (2021) 1-10, https://doi.org/10.1007/ s00114-020-01708-8.

[30] A.A. Menezes, J. Cumbers, J.A. Hogan, A.P. Arkin, Towards synthetic biological approaches to resource utilization on space missions, J. R. Soc. Interface 12 (2015) 20140715, https://doi.org/10.1098/rsif.2014.0715.

[31] S.N. Nangle, M.Y. Wolfson, L. Hartsough, N.J. Ma, C.E. Mason, M. Merighi, V. Nathan, P.A. Silver, M. Simon, J. Swett, D.B. Thompson, M. Ziesack, The case for biotech on Mars, Nat. Biotechnol. 38 (2020) 401-407, https://doi.org/10.1038/ s41587-020-0485-4.

[32] F. Vollrath, D.P. Knight, Liquid crystalline spinning of spider silk, Nature 410 (2001) 541-548, https://doi.org/10.1038/35069000.

[33] A. Micsonai, F. Wien, L. Kernya, Y.H. Lee, Y. Goto, M. Réfrégiers, J. Kardos, Accurate secondary structure prediction and fold recognition for circular dichroism spectroscopy, Proc. Natl. Acad. Sci. USA 112 (2015) E3095-E3103, https://doi.org/ 10.1073/pnas.1500851112.

[34] W. Finnigan, A.D. Roberts, C. Ligorio, N.S. Scrutton, R. Breitling, J.J. Blaker, E. Takano, The effect of terminal globular domains on the response of recombinant mini-spidroins to fiber spinning triggers, Sci. Rep. 10 (2020) 10671, https:// doi.org/10.1038/s41598-020-67703-1.

[35] M.R. Wilkins, E. Gasteiger, A. Bairoch, J.C. Sanchez, K.L. Williams, R.D. Appel, D.F. Hochstrasser, Protein identification and analysis tools in the ExPASy server, Methods Mol. Biol. 112 (1999) 531-552, https://doi.org/10.1385/1-59259-584-7: 531.

[36] P. Chindaprasirt, S. Hatanaka, N. Mishima, Y. Yuasa, T. Chareerat, Effects of binder strength and aggregate size on the compressive strength and void ratio of porous concrete, Int. J. Miner. Metall. Mater. 16 (2009) 714-719, https://doi.org/ 10.1016/S1674-4799(10)60018-0.

[37] K. McNeil, T.H.K. Kang, Recycled concrete aggregates: a review, Int. J. Concr. Struct. Mater. 7 (2013) 61-69, https://doi.org/10.1007/s40069-013-0032-5.

[38] D.P. Knight, F. Vollrath, Liquid crystals and flow elongation in a spider's silk production line, Proc. R. Soc. B Biol. Sci. 266 (1999) 519-523, https://doi.org/ 10.1098/rspb.1999.0667.

[39] M. Heim, D. Keerl, T. Scheibel, Spider silk: from soluble protein to extraordinary fiber, Angew. Chem. Int. Ed. 48 (2009) 3584-3596, https://doi.org/10.1002/ anie. 200803341.

[40] V. Vetri, F. Librizzi, M. Leone, V. Militello, Thermal aggregation of bovine serum albumin at different $\mathrm{pH}$ : comparison with human serum albumin, Eur. Biophys. J. 36 (2007) 717-725, https://doi.org/10.1007/s00249-007-0196-5.

[41] A. Bujacz, Structures of bovine, equine and leporine serum albumin, Acta Crystallogr. Sect. D Biol. Crystallogr. 68 (2012) 1278-1289, https://doi.org/ 10.1107/S0907444912027047.

[42] G.J. Brownsey, T.R. Noel, R. Parker, S.G. Ring, The glass transition behavior of the globular protein bovine serum albumin, Biophys. J. 85 (2003) 3943-3950, https:// doi.org/10.1016/S0006-3495(03)74808-5.

[43] A.K. Shaw, S.K. Pal, Spectroscopic studies on the effect of temperature on $\mathrm{pH}-$ induced folded states of human serum albumin, J. Photochem. Photobiol. B Biol. 90 (2008) 69-77, https://doi.org/10.1016/j.jphotobiol.2007.11.003.

[44] C. Rose, A. Parker, B. Jefferson, E. Cartmell, The characterization of feces and urine: a review of the literature to inform advanced treatment technology, Crit. Rev. Environ. Sci. Technol. 45 (2015) 1827-1879, https://doi.org/10.1080/ 10643389.2014.1000761.

[45] J. Hauslage, S.M. Strauch, O. Eßmann, F.W.M. Haag, P. Richter, J. Krüger, J. Stoltze, I. Becker, A. Nasir, G. Bornemann, H. Müller, T. Delovski, T. Berger, A. Rutczynska,
K. Marsalek, M. Lebert, Eu:CROPIS - "euglena gracilis: combined regenerative organic-food production in space" - a space experiment testing biological life support systems under lunar and martian gravity, Microgravity Sci. Technol. 30 (2018) 933-942, https://doi.org/10.1007/s12217-018-9654-1.

[46] S. Babakhanova, S. Baber, F.B. Zazzera, E. Hinterman, J. Hoffman, J. Kusters, G. Lordos, J. Lukic, F. Maffia, P. Maggiore, L. Mainini, A. Moccia, H. Nowak, T. Schneiderman, S. Sciarretta, S. Seager, S. Seaman, T. Smith, N. Stamler, V. Sumini, Z. Zhan, Mars garden: an engineered greenhouse for a sustainable residence on mars, in: AIAA Propuls. Energy Forum Expo, vol. 2019, 2019, p. 4059, https://doi.org/10.2514/6.2019-4059.

[47] C.T. Huang, M.L. Chen, L.L. Huang, I.F. Mao, Uric acid and urea in human sweat, Chin. J. Physiol. 45 (2002) 109-115.

[48] J.H. Thaysen, N.A. Thorn, Excretion of urea, sodium, potassium and chloride in human tears, Am. J. Physiol. 178 (1954) 160-164, https://doi.org/10.1152/ ajplegacy.1954.178.1.160.

[49] G.W.W. Wamelink, J.Y. Frissel, W.H.J. Krijnen, M.R. Verwoert, P.W. Goedhart, Can plants grow on mars and the moon: a growth experiment on mars and moon soil simulants, PloS One 9 (2014), e103138, https://doi.org/10.1371/ journal.pone.0103138.

[50] C. Leggio, L. Galantini, P.V. Konarev, N.V. Pavel, Urea-induced denaturation process on defatted human serum albumin and in the presence of palmitic acid, J. Phys. Chem. B 113 (2009) 12590-12602, https://doi.org/10.1021/jp904330v.

[51] F. Hammami, H. Ghalla, S. Nasr, Intermolecular hydrogen bonds in urea-water complexes: DFT, NBO, and AIM analysis, Comput. Theor. Chem. 1070 (2015) 40-47, https://doi.org/10.1016/j.comptc.2015.07.018.

[52] I.S. Johnson, Human insulin from recombinant DNA technology, Science 219 (1983) 632-637, https://doi.org/10.1126/science.6337396.

[53] A. Rising, J. Johansson, Toward spinning artificial spider silk, Nat. Chem. Biol. 11 (2015) 309-315, https://doi.org/10.1038/nchembio.1789.

[54] M. Andersson, Q. Jia, A. Abella, X.Y. Lee, M. Landreh, P. Purhonen, H. Hebert, M. Tenje, C.V. Robinson, Q. Meng, G.R. Plaza, J. Johansson, A. Rising, Biomimetic spinning of artificial spider silk from a chimeric minispidroin, Nat. Chem. Biol. 13 (2017) 262-264, https://doi.org/10.1038/nchembio.2269.

[55] C.H. Bowen, B. Dai, C.J. Sargent, W. Bai, P. Ladiwala, H. Feng, W. Huang, D.L. Kaplan, J.M. Galazka, F. Zhang, Recombinant spidroins fully replicate primary mechanical properties of natural spider silk, Biomacromolecules 19 (2018) 3853-3860, https://doi.org/10.1021/acs.biomac.8b00980.

[56] R.A. Le Feuvre, N.S. Scrutton, A living foundry for Synthetic Biological Materials: a synthetic biology roadmap to new advanced materials, Synth. Syst. Biotechnol. 3 (2018) 105-112, https://doi.org/10.1016/j.synbio.2018.04.002.

[57] D.C. Friedman, A.D. Ellington, Industrialization of Biology, The National Academies Press, Washington, DC, 2015, https://doi.org/10.1021/acssynbio.5b00190.

[58] A. Pena-Francesch, B. Akgun, A. Miserez, W. Zhu, H. Gao, M.C. Demirel, Pressure sensitive adhesion of an elastomeric protein complex extracted from squid ring teeth, Adv. Funct. Mater. 24 (2014) 6227-6233, https://doi.org/10.1002/ adfm.201401534.

[59] A. Pena-Francesch, H. Jung, M.C. Demirel, M. Sitti, Biosynthetic self-healing materials for soft machines, Nat. Mater. 19 (2020) 1230-1235, https://doi.org/ 10.1038/s41563-020-0736-2.

[60] A.E. Jakus, K.D. Koube, N.R. Geisendorfer, R.N. Shah, Robust and elastic lunar and martian structures from 3D-printed regolith inks, Sci. Rep. 7 (2017) 44931, https:// doi.org/10.1038/srep44931.

[61] S. Benvenuti, F. Ceccanti, X. De Kestelier, Living on the moon: topological optimization of a 3D-printed lunar shelter, Nexus Netw. J. 15 (2013) 285-302, https://doi.org/10.1007/s00004-013-0155-7.

[62] S.L. Taylor, A.E. Jakus, K.D. Koube, A.J. Ibeh, N.R. Geisendorfer, R.N. Shah, D.C. Dunand, Sintering of micro-trusses created by extrusion-3D-printing of lunar regolith inks, Acta Astronaut. 143 (2018) 1-8, https://doi.org/10.1016/ j.actaastro.2017.11.005.

[63] T. Rousek, K. Eriksson, O. Doule, SinterHab, Acta Astronaut. 74 (2012) 98-111, https://doi.org/10.1016/j.actaastro.2011.10.009.

[64] P.E. Hintze, S. Quintana, Building a lunar or martian launch pad with in situ materials: recent laboratory and field studies, J. Aero. Eng. 26 (2013) 134-142, https://doi.org/10.1061/(asce)as.1943-5525.0000205.

[65] J.K. Román, J.J. Wilker, Cooking chemistry transforms proteins into high-strength adhesives, J. Am. Chem. Soc. 141 (2019) 1359-1365, https://doi.org/10.1021/ jacs.8b12150.

[66] M.R. Lin, J.E. Ritter, L. Rosenfeld, T.J. Lardner, Measuring the interfacial shear strength of thin polymer coatings on glass, J. Mater. Res. 5 (1990) 1110-1117, https://doi.org/10.1557/JMR.1990.1110.

[67] J. Lehne, F. Preston, Making Concrete Change: Innovation in Low-Carbon Cement and Concrete, Chatham House - International Affairs Think Tank, 2018. 